\title{
EL «TEATRO FRANCÉS» DE MADRID $(1851-1861)^{1}$
}

\author{
PEDRO OJEDA \\ Universidad de Burgos \\ E IRENE VALLEJO \\ Universidad de Valladolid
}

La influencia del teatro francés en nuestro país a partir de las últimas décadas del siglo XVIII fue notable ${ }^{2}$. En los teatros españoles se vieron re-

\footnotetext{
${ }^{1}$ El título del trabajo hace referencia no tanto a las representaciones de teatro francés en Madrid como al hecho de que las diferentes empresas que se constituyen para dar funciones durante estos años se denominarán «Teatro Francés».

${ }^{2}$ El mejor repertorio bibliográfico al respecto se encuentra en F. LAFARGA, Bibliografía anotada de estudios sobre recepción de la cultura francesa en España (siglos XVI-XX), Barcelona, PPU, 1998. Sobre esta materia, véanse, entre otros, los siguientes trabajos: R. ANDIOC y M. Coulon, Cartelera teatral madrileña del siglo XVIII (1708-1808), Toulouse, Presses Universitaires du Mirail, 1996; E. COBOS CASTRO, Traductores al castellano de obras dramáticas francesas (1830-1930), Córdoba, Universidad, 1998; R. DENGLER, «El melodrama francés. Su proceso de penetración en España, su proyección y acogida en las tablas madrileñas en la época romántica, 1830-1850», Récifs, 8, 1986, pp. 138-160; R. DENGLER, «La traducción del vaudeville francés en España durante la época romántica», en B. LepinetTe, M. ${ }^{a}$ A. Olivares y E. Sopeña (eds.), Actas del Primer Coloquio internacional de Traductología, Valencia, Universitat, 1991; R. DENGLER, «El teatro francés en traducción como transmisor del ideario burgués (1830-1850)», en C. ORTIZ DE ZÁRATE (ed.), Mundos ibéricos y mundos francófonos, Las Palmas de Gran Canaria, Universidad, 1995, pp. 99-109; M. ${ }^{a}$ J. GARCÍA GARROSA y G. VeGA GARCía-LuENGOS, «Las traducciones del teatro francés (1700-1835). Más impresos españoles», en Cuadernos de Estudios del Siglo XVIII, Oviedo, 1991, n. ${ }^{\circ} 1$, pp. 85-104; F. LAFARGA, Las traducciones espanolas del teatro francés (1700-1835). I. Bibliografía de impresos, Barcelona, Universidad, 1983 y Las traducciones españolas del teatro francés (1700-1835). II. Catálogo de manuscritos, Barcelona, Universidad, 1988; F. LAFARGA y R. DENGLER (eds.), Teatro y traducción, Barcelona, Universitat Pompeu Fabra, 1995; F. LAFARGA, C. PAlacios y A. SAURA (eds.), Neoclásicos y románticos ante la traducción, Murcia, Universidad, 2002; P. MENARINI y otros, El teatro romántico español (1830-1850). Autores, obras, bibliografía, Bolonia, Atesa, 1982; y M. ${ }^{a}$ J. RODRíGUEZ SÁNCHEZ DE LEÓN, «Las traducciones del teatro europeo y el restablecimiento del teatro nacional», en La crítica dramática en España (1789-1833), Madrid, CSIC, 1999, pp. 127-167.
}

Rlit, LXV, 130 (2003), 413-446 
presentadas numerosas adaptaciones, arreglos y traducciones más o menos libres de textos franceses. Esta influencia será constante y, en la primera mitad del siglo XIX, su presencia es aun mayor, como lo demuestra la cartelera teatral madrileña ${ }^{3}$. Se viene estudiando desde hace algunos años esta cuestión, pero en lo que no se ha reparado hasta la fecha es que desde 1851 hasta 1861 tuvieron lugar en Madrid numerosas representaciones de teatro francés, en ese idioma, interpretadas por compañías francesas, con las repercusiones que esto tuvo para la escena española. De este asunto es del que nos proponemos tratar en las páginas siguientes.

Cabe preguntarse por las razones que facilitaron el hecho de que, a partir de 1851 , se pudiera asistir con total normalidad a espectáculos en francés en la capital española. En primer lugar, el fenómeno no es exclusivamente madrileño. En diferentes ciudades de todo el continente europeo se promovió la presencia de empresas teatrales francesas respondiendo, por una parte, al predominio de la cultura de ese país. París seguía siendo el centro de las miradas de todo hombre de letras que se preciara. Con relación al teatro, ya se había generado un gusto por lo francés que venía desde el siglo XVIII y que se agudizó en las primeras décadas del XIX, y que, en el caso español, llegó a la culminación con el Tercer Imperio. Las clases acomodadas madrileñas vieron un ejemplo a imitar en la corte del emperador y el furor por lo afrancesado se acentuó entre los españoles, imitando sobre todo el tono de refinamiento, las comodidades, modas y costumbres. Y todo ello a pesar de la severa mirada de muchos escritores que denunciaban desde las páginas de periódicos y revistas ilustradas, que también imitaban lo francés, la pérdida de lo netamente español, como ya encontramos en Mesonero Romanos, por ejemplo. El teatro, como uno de los espacios preferentes para la diversión de la burguesía de la época, recibe plenamente el impacto de este nuevo afrancesamiento de los gustos. Algunos lo viven como algo preocupante, insistiendo en la necesidad de volver a los clásicos o a los modelos españoles del último medio siglo, desde Moratín hasta los más recientes románticos, obviando que a estos también se les acusó de afrancesamiento en sus inicios. Sin embargo, otros vieron la faceta positiva de este influjo. Así, un viajero como Sarmiento denuncia la situación de un teatro anclado en la inverosimilitud del verso y producido en un ambiente tan provinciano y cerrado como Madrid («Madrid, aunque real y muy noble, es siempre la villa de Madrid»), y no duda en ponerse del

\footnotetext{
${ }^{3}$ Cartelera teatral madrileña. I: 1830-1839, Madrid, CSIC, 1961; F. HERRERO SALGADO, Cartelera teatral madrileña, II: años 1840-1849, Madrid, CSIC, 1963; I. VALlejo y P. OJEDA, El teatro en Madrid a mediados del siglo XIX. Cartelera teatral (1854-1864), Valladolid, Universidad, 2002. En buena medida, el presente artículo pretende completar los datos correspondientes al teatro francés de este último trabajo, ampliando el período de estudio, añadiendo datos en el índice de autores y obras y estudiando las características del fenómeno del Teatro Francés en España.
} 
lado del teatro parisino, que ha sufrido, según sus palabras, una revolución que le ha llevado a su apogeo ${ }^{4}$. Hay que señalar que, sin la regularidad que se da en el período estudiado para el Teatro Francés, también asistimos a varias estancias de compañías de otras nacionalidades por estas fechas, especialmente italianas, como la de Adelaida Ristori o la de Carolina Santoni, además de la presencia regular de artistas de diferentes países que se dedican especialmente a conciertos de música y al género más amplio de las variedades (escapistas, magos, mentalistas, prestidigitadores, gimnastas, etc.).

El gusto por la cultura francesa, con su mayor o menor componente de moda externa, tuvo el efecto de crear un público ávido de novedades provenientes de Francia. Son muchos los miembros de las clases acomodadas que conocían mejor o peor el idioma francés. Y estos son mayoritariamente pertenecientes a los sectores sociales qúe consideraban el teatro como uno de los espacios de obligada asistencia para toda persona de buen tono que quisiera ver y ser vista. Si a este público le sumamos la nutrida colonia de franceses que residen en Madrid de forma permanente o circunstancial, por motivos de trabajo o de negocios, hallamos el núcleo de espectadores potenciales de los espectáculos franceses. Tampoco es de desdeñar la presencia de aquellos que, sin conocer el idioma, asisten por moda, interés u otras razones -entre las que podría estar, como veremos, la atracción por lo picante de algunos textos y la forma de actuar de los actores- a las funciones del Teatro Francés, y de los que se van a burlar los críticos en algunas ocasiones. Semanas después del debut de la primera compañía francesa, se señalaba en el Diario Oficial de Avisos de Madrid:

por lo demás ha concluido ya la curiosidad, y el público que allí asiste, lo forman solamente algunas personas que entienden el francés, y un corto número de los que no lo entienden, pero que no quieren pasar por la vergüenza de decirlo. La fisonomía de estos es una cosa digna de verse: abren mucho los ojos y se sonríen a todo para no equivocarse cuando deban reírse. En nuestra opinión, el que no entienda el francés, hace allí lo mismo que los perros en misa ${ }^{5}$.

${ }^{4}$ Viajes en Europa, África i América (1845-1847), en Obras, vol. V, Santiago de Chile, Gutemberg, 1886, p. 172. Para Sarmiento, uno de los males que afectaban a los escritores madrileños era lo estrecho de su círculo: hubiera bastado con asistir ocho días a la tertulia de Romea, al Casino y al café de los Suizos, antes del Príncipe, para conocer a todos los que significaban algo en la capital española. Esta mirada negativa sobre Madrid, le lleva a afirmar: "Y esto no por falta de talento, que es común en España como lo es en todas partes donde nacen niños con cráneo bien desenvuelto, sino por falta de espectáculo real en la sociedad en que viven, rudimental aún, simple en sus virtudes, como en sus crímenes y en sus vicios. Esta simplicidad de la vida en la real villa, va hasta ligar al público con su actor y su actriz, y hacerle tomar parte en sus desavenencias domésticas» (Ibídem, p. 175).

${ }^{5}$ Diario Oficial de Avisos de Madrid, domingo 30 de noviembre de 1851. A lo largo de los años que duró la presencia de las compañías francesas, se insistió en este 
Con estos espectadores, el Teatro Francés logra un público habitual y muy fiel que sostiene, a través de los abonos, las diferentes empresas que se suceden en el tiempo, como señalan en varias ocasiones las reseñas de las funciones. Sin embargo, en este mismo sector de los espectadores que lo nutría, encontraba el Teatro Francés parte de su fragilidad. En primer lugar, el público de los espectáculos franceses era casi idéntico al de la ópera, con la que no podía competir en calidad artística ni en importancia social. Esta coincidencia fue señalada ya por Eugenio de Ochoa en un inteligente artículo publicado en La España en el que, comentando la novedad de la venida de la primera compañía francesa, adelantaba ya buena parte de sus ventajas e inconvenientes:

Trátase de la venida de una buena compañía francesa, cuyo debut se anuncia ya como positivo para $1^{\circ}$ de noviembre próximo. Mucho celebraremos que este proyecto se lleve a ejecúción y obtenga el buen éxito que merece, como también, que si así sucede, la compañía francesa alterne sus representaciones con las de la ópera italiana para evitar la comparación demasiado inmediata en una misma escena de nuestros actores con los de fuera, desventajosa para unos y otros. Cada teatro tiene su público especial, y el que ha de gustar de la comedia francesa acudirá con más gusto a la ópera que a funciones parecidas a las que da ahora la $\mathrm{Cruz}^{6}$.

De ahí que el Teatro Francés se beneficie de la suspensión de la actividad del Real o del final de la temporada de éste, viendo aumentadas sus recaudaciones, como sucedió en diferentes momentos ${ }^{7}$. Por otra parte, la mayoría de los espectadores habituales, en especial los franceses dedicados a sus negocios en Madrid, asisten casi exclusivamente los días festivos, encontrándose bastante desangelado el local el resto de la semana, excepto cuando hay funciones de gran calidad o novedad.

El Teatro Francés, durante toda su permanencia en la década estudiada, mantuvo líneas similares de actuación, parecido objetivo empresarial, el predominio del vaudeville entre las modalidades dramáticas puestas en escena, e idéntica percepción del fenómeno entre el público y la crítica madrileña. Sin embargo, no fue una institución consolidada ni tuvo más continuidad entre las diferentes temporadas que la permanencia, en algunos períodos, del mismo empresario. Esto explica la fragilidad del empeño, a la vez que su desaparición.

hecho. Así, en La Ilustración de Madrid del 16 de noviembre de 1852 se recomienda al lector de provincias: «Si entendéis el francés debéis asistir a este coliseo, y aunque no lo entendáis también debéis ir. Consolaos con que son muchos los que van todas las noches y no lo entienden». La prensa publicará varios chistes al respecto, como la «simpática anécdota» aparecida en La Iberia (25 de octubre de 1856), bajo el título de «El paleto y el intérprete».

${ }^{6}$ Artículo reproducido en la Gaceta de Madrid, 13 de octubre de 1851.

${ }^{7}$ Así lo señalan los periódicos en marzo de 1859 y abril de 1860. 
Durante estos diez años, algunos empresarios se arriesgaron a traer compañías francesas a Madrid, como se hacía en varias capitales europeas. En ese período se dieron nueve temporadas de teatro francés en las versiones originales de los textos por parte de actores de aquel país. La presencia se interrumpió en la temporada 1854-1855, sin duda, por la situación revolucionaria que atravesaba España en el verano del 54, y se dio por concluida en 1861 sin ninguna explicación que lo justifique.

Los resultados artísticos fueron irregulares, alternando temporadas de buen tono medio con otras que pueden considerarse un fracaso, pero la importancia para el mundo teatral de la capital es indiscutible. Aunque muchos españoles pudieran viajar a París y asistir allí a los espectáculos teatrales, es con motivo de las representaciones en Madrid cuando el fenómeno se amplía a un público más extenso y heterogéneo. Son de gran interés, sobre todo, las relaciones que pudieron establecerse con las personas que en la capital española estaban vinculadas al mundo teatral, especialmente dramaturgos, empresarios y actores. Todas estas ramificaciones fueron vistas con esperanza por parte de los más avezados críticos del momento. Eugenio de Ochoa, en el artículo citado de La España, adelantaba lo que se esperaba con la llegada de la primera compañía francesa, con especial énfasis en lo que respecta a la importancia para los actores españoles, por lo que pudieran aprender de sus colegas, aunque quizá resultasen perjudicados por la competencia y comparación:

\footnotetext{
En cuanto a la utilidad positiva que pueda tener para los adelantos del arte en España la venida de una compañía francesa, es cuestión que no se puede resolver por ahora, pues está naturalmente subordinada al mérito mayor o menor de la compañía: si no vale gran cosa, poco ganaremos con que venga; si es como cualquiera de las de París (no pedimos más), entonces mucho podrán aprender en ella nuestros actores, aun cuando no sepan bien el francés. Según nuestras noticias, la compañía que nos traen es muy buena.
}

Fueron cuatro los locales que alquilaron las diferentes empresas. En la Cruz estuvieron las dos primeras temporadas (1851-1852 y 1852-1853), para pasar después al Instituto Español (1853-1854), Lope de Vega (1855-1856 y 1856-1857) y al Variedades (1857-1858, 1858-1859, 1859-1860 y $1860-$ 1861). Como se puede apreciar, excepto el vetusto local de la Cruz, el resto son espacios escénicos de segundo orden, aunque suficientes y bien conceptuados entre los espectadores madrileños de la época. El coliseo de la Cruz, que vivía sus últimas temporadas de existencia, se había empobrecido en condiciones materiales y artísticas, y en las descripciones de estos años merece pocos elogios. F. Montemar, en un interesante artículo publicado en La Ilustración, en el que comenta la influencia del Decreto sobre Teatros aún vigente en 1852, en cuanto a la tradicional duración de los contratos para el año cómico, y después de repasar las últimas produccio- 
nes vistas en los teatros del Príncipe, Drama, Circo y Cruz, dice de éste y su posición en el panorama de los locales madrileños:

Este coliseo tiene cierto olorcillo a teatro de provincia; pero a juicio de los inteligentes, este es su más bello atractivo, porque de este modo puede dar funciones a dos reales la entrada, con grandes carteles que dicen a beneficio del público; y cuando no bastan los atractivos de una capital de provincia se recurre a los atractivos de aldea, colocando sobre el cartel alguna estampa con una de las principales escenas del drama que se representa, escogiendo para mayor ilusión aquellas en que asomen la cabeza unos cuantos majos haciendo fuego con sus trabucos; pero una vez que así logran llamar gente y dar de comer a unas cuantas familias, dejémoslos en paz: tengamos paciencia y suframos, que puesto que vamos a entrar en Semana Santa, justo es recordar que más padeció Cristo por nosotros ${ }^{8}$.

A pesar de lo dicho, se intentó siempre introducir reformas y mejoras en los locales que cumplierán las exigencias de comodidad del público de clase alta que acudía a estas funciones.

Las temporadas del Teatro Francés fueron en todos los casos de duración considerablemente más corta que las de compañías nacionales. En algunos casos, de apenas unos meses. En consecuencia, los locales en los que trabajaron dividieron la temporada con empresas españolas cuyas compañías, en los períodos en los que el teatro era ocupado por la extranjera, marchaban a provincias. En una ocasión, en la temporada en la que se encontraban en el Instituto Español, alternaron durante semanas con una española, por circunstancias que ya se verán.

La primera temporada se inició el 5 de noviembre de $1851^{9}$ y terminó el 4 de marzo de 1852. El director de la troupe era Mr. Bernard y entre los componentes (más de 17, sin contar los profesores de la orquesta) ${ }^{10}$ hallamos algunos ya conocidos en los teatros parisinos como el de la Porte de Saint Martín, Gimnasio, Vaudeville, República, etc. Otros procedían de las provincias francesas. Como posible incorporación al elenco se anunciaban los célebres Ravel o Rachel ${ }^{11}$. Ya desde aquel primer momento, los

${ }^{8}$ La Ilustración, 3 de abril de 1852.

9 Se había anunciado en inicio para el $1 .^{\circ}$ de noviembre, se retrasó al 3 y, finalmente, al 5, suprimiéndose de la función inaugural L'Union des Arts, prólogo en verso compuesto especialmente para la apertura del Teatro Francés de Madrid, puesto que en los ensayos se vio que la función duraba más de lo acostumbrado (Diario Oficial de Avisos de Madrid, 31 de octubre de 1851).

${ }^{10}$ El número es más o menos el mismo de una compañía española de tipo medio. Véase el listado inicial en la Gaceta de Madrid, 13 de octubre de 1851. A lo largo de la temporada hubo diferentes incorporaciones.

11 Nombres de celebridades se barajaron a lo largo de varias temporadas, sin conseguir que viniera a Madrid ninguno de los grandes actores parisinos que estaban en su máximo apogeo. Al menos en otra ocasión se pretendió la contratación de la Rachel. Fue en la segunda temporada y también resultó un intento infructuoso. La noticia apareció en varios periódicos madrileños. Así, en la Gaceta de Madrid (13 de enero de 1853) 
espectadores pudieron comprobar que los precios eran caros comparados con los teatros de verso españoles ${ }^{12}$. También se observó pronto que este

se reproduce un «curioso artículo» del Heraldo en el que se puntualiza que la función del viernes siguiente era la última hasta el próximo invierno «pues aunque el señor Peral había escrito a París con el objeto de procurar la venida de Rachel para abril, las exigencias de dicha actriz son tan exorbitantes respecto a los recursos pecuniarios del público que en Madrid asiste a representaciones francesas, que no es posible en manera alguna volver a pensar en ello. Los Sres. Beneilli y compañía, agentes de teatro en París, dicen en su carta del 5 al Sr. Peral lo que sigue: «Hemos tenido una larga conferencia con Mr. Rafael Félix (hermano de Mlle. Rachel), y he aquí sus condiciones. Dará 20 representaciones durante el mes de octubre; de cuatro en cuatro descansará un día, y repetirá cada función dos veces. Cien mil francos por ella y su compañía. Ejecutará el repertorio por V. designado.» El repertorio designado por el Sr. Peral es el siguiente: Tragedias: Phédre.- Andromaque.- Les Horaces.- Polyeucte.- Bajazet.- Marie Stuart. DRAMAS: Diane.- Angelo, Tyran de Padoue.- Louse de Lignerolles.- Adrienne Lecouvreur. La cuenta de lo pedido por Rachel no puede 'ser más redonda. Diez y nueve mil reales por noche, que con tres mil más a que ascendiesen los gastos ordinarios, suman veinte y dos mil. Dejamos al buen juicio de nuestros lectores el considerar si el público de Madrid llenaría 20 noches el teatro de la Cruz, de bote en bote, pagando los billetes a doble precio, y en Octubre, cuando hay abiertos otros seis teatros, por ver a Mlle. Rachel, aunque viniese con Talma. Y suponiendo que sucediese, lo que no es posible que suceda, después de todo esto, el empresario sólo sacaría los gastos. Grande es el mérito de Rachel (no así el de la compañía con que viaja); pero aun entre sus compatriotas ha representado en teatros de segundo y tercer orden, no logrando de entrada la quinta parte de lo que ahora pide, y en Bayona la hemos visto estando el teatro medio desocupado».

12 El precio de los abonos era:

\begin{tabular}{|l|c|c|}
\hline & $\begin{array}{c}60 \text { representaciones, hecha la baja } \\
\text { del } 50 \%\end{array}$ & $\begin{array}{c}\text { 30 representaciones, hecha la baja } \\
\text { del } 40 \%\end{array}$ \\
\hline Palcos bajos sin entradas & 1.500 & 900 \\
\hline Íd. Principales sin íd. & 1.200 & 720 \\
\hline Íd. Segundos, sin id. & 900 & 540 \\
\hline Íd. de galería alta, sin id. & 600 & 360 \\
\hline Butacas sin id. & 360 & 216 \\
\hline Lunetas sin íd. & 180 & 108 \\
\hline Sillones de galeria baja sin id. & 240 & 144 \\
\hline Delanteras de palco principal sin id. & 180 & 108 \\
\hline İd. de palco 2 ${ }^{\circ}$ sin íd. & 120 & 72 \\
\hline Sillones de galería alta sin id. & 120 & 72 \\
\hline Delantera de anfiteatro sin id. & 120 & 72 \\
\hline
\end{tabular}

$\mathrm{Al}$ anuncio de los precios se adjuntaba una nota especificando que un «programa que comprende el título y la distribución de las piezas, como asimismo un análisis de la representación o argumento; todo en español, se venderá a la puerta y en el interior del teatro. Precio, dos cuartos» (Diario Oficial de Avisos de Madrid, 31 de octubre de 1851). Lo caro de los precios merecerá varios comentarios a lo largo de los años, algunos irónicos, como el aparecido en La Iberia el 5 de diciembre de 1855: «Lo que nos parece exagerado es el precio de las localidades, aunque si bien se considera esta exageración se convertirá en una gran contra para el empresario de este coliseo, que al fin y al cabo vendrá a moderarse en sus exigencias, ilustrado con la ausencia del público». 
tipo de compañías, sin contar con grandes notoriedades, integradas por nombres de segundo orden, debían tener como aspiración lograr un regular elenco de actores; por las características interpretativas de sus miembros, el género en el que mejor podían desarrollar sus habilidades era el vodevil, que se convirtió en la modalidad por excelencia en las representaciones. Asimismo, desde el inicio, se apreció que la función debía basarse no sólo en las obras largas y que convenía dar el suficiente realce a las piezas en un acto. Aunque no escasearon las obras de tres actos, muchas funciones del Teatro Francés se componían de tres o hasta cuatro piezas breves a las que se añadían canciones ${ }^{13}$, escenas o bailes en los entreactos. Algunos días se prologaba con una sinfonía. El resultado artístico de la primera temporada fue más que notable y se recordó durante mucho tiempo la calidad media de los actores y las piezas puestas en escena, a lo que contribuiría no poco el efecto sorpresa.

La segunda temporada, que comenzó el 28 de septiembre de 1852 y terminó el 14 de enero de 1853 , contó con una mala compañía que no satisfizo las expectativas generadas el primer año. El empresario, Sr. Daiglemont, no acertó ni con los actores contratados, entre los que no había nombres de relieve, ni con las piezas elegidas para sus primeras funciones ${ }^{14}$. El desastre siguió agudizándose, con la prohibición de representar alguna pieza una vez ya estrenada, y sólo pudo paliarse un tanto a partir de la llegada de la actriz Mlle. Michaux y, sobre todo, del actor Neuville, primer gracioso. El ambiente interno de la compañía no debió ser bueno, puesto que saltó a la prensa el descontento de los actores con el empresario, que les negaba los beneficios de Nochebuena, además de los particulares, como era usual en la escena madrileña ${ }^{15}$.

\footnotetext{
${ }^{13}$ Entre otras, se pueden encontrar: Les Belles de nuit, Ça n'est pas perdu, Cliquet le mythologiste, Le Docteur Isambert, Les Tribulations d'un choriste, y Les Tribulations d'un portier.

${ }^{14}$ El crítico de la Gaceta de Madrid (10 de octubre de 1852) censuró duramente al director-empresario por traer actores intolerables para el público. El Sr. Daiglemont «se ha equivocado lastimosamente, pues la sociedad que concurre al teatro de la Cruz, tan culta como equitativa, si bien premia el mérito, se muestra justamente severa con lo que severidad merece». Piensa que de la compañía sólo deberían quedar el Sr. y la Sra. Martin y la Srta. Picard. Los otros no eran dignos de trabajar ante el público de Madrid. Como un posible arreglo, la empresa anunciaba la venida de la Srta. Michaux, del teatro de Variétés de Paris. Ese año los espectadores, a diferencia del anterior, habían abandonado este teatro. El repertorio también le resultaba deplorable al mismo crítico. Cita algunos títulos que le parecen «antiguallas» (Chevalier de Saint Georges, La chambre nuptiale, Le mari de la dame de choeurs). Consideraba que si la compañía francesa quería seguir trabajando se imponía un cambio de rumbo.

15 «(...)además de no tener beneficios particulares los artistas del teatro francés, parece que tampoco piensa Mr. Daiglemont concederles el que es siempre costumbre en Madrid dar a las compañías dramáticas el día de Nochebuena. No podemos menos de sentir tan poco generoso desprendimiento de parte del director empresario para con unos
} 
La tercera temporada comenzó el lunes 10 de octubre de 1853 y terminó el miércoles 22 de febrero de 1854. Después del fracaso que supuso la gestión de Daiglemont, el nuevo director, Mr. Jules Bernard planteó un proyecto excesivamente ambicioso para su capacidad. Contrató dos compañías, una de ópera y otra dramática, especializada en vaudeville, y comenzó las funciones de la temporada con la primera. Sin embargo, los cantantes no eran buenos y las entradas se resintieron. Las críticas se acumularon y el propio Bernard hubo de publicar un comunicado en el Heraldo, periódico que se había convertido desde meses antes en el portavoz y defensor de las empresas del Teatro Francés, en el que se manifestaba dispuesto a dar un giro positivo a la situación:

Señores redactores: Nadie puede ser un buen juez en causa propia; y yo veo, aunque por desgracia tarde, que me he engañado al elegir la primera ópera que he puesto en escena. Lleno de'respeto hacia los fallos del público y la opinión de la prensa, redoblo mis esfuerzos por presentar pronto obras de menores pretensiones y de más fácil ejecución. Se están ensayando óperas bufas; y el Caid, de Amroise Thomas; el Domino noir, y Fra Diavolo, de Auber, serán representadas dentro de un corto plazo. Me atrevo a recurrir a vuestra bondad, que nunca me ha desairado, esperando que os dignaréis publicar este comunicado, en el que suplico al público y a la prensa que no precipiten su fallo, y esperan para juzgar del mérito de los artistas a que cada uno de ellos haya tenido ocasión de presentarse en los papeles que convienen a sus facultades.

Once artistas no han debutado aún: y el vaudeville, que tanto gusta en Madrid, será, según creo, una diversión agradable, y podrá alternar con las funciones compuestas exclusivamente de ópera. Yo espero todavía que los protectores del teatro francés, persuadidos de que no consultaré jamás sino su gusto y sus deseos, no retirarán a una empresa que tiene necesidad de apoyo su benevolencia y su solicitud. En unos momentos en que una compañía española va a presentarse ante el público parisiense, Madrid no se dejará vencer en la práctica de la hospitalidad. Tengo el honor de \&c. $=$ Bernard $^{16}$.

Con la llegada del elenco dramático, que dio su primera función con éxito el 18 de octubre, se vio con claridad la difícil situación de la compañía de ópera y los críticos de los periódicos animaban a Bernard a prescindir de ella. Como consecuencia final, el empresario no pudo hacer frente a los apuros económicos y desapareció de Madrid dejando, sin más, a actores, abonados y demás empleados. La crisis la salva una nueva empresa que se hace cargo del local con el nombre de Teatro del Instituto y que mantendrá una doble compañía, la francesa dramática y una española, alternándolas en una parte del resto de la temporada, y prescindiendo definitivamente de la compañía de ópera:

artistas a quienes tanto hace trabajar, y a los que tan escasos sueldos tiene señalados» (Gaceta de Madrid, 21 de diciembre de 1852).

${ }^{16}$ Reproducido en la Gaceta de Madrid, 17 de octubre de 1853. 
La nueva dirección, que bajo los auspicios de la Sociedad del Instituto Español ha quedado a cargo de los artistas que componen la compañía francesa, agradecida a la benevolencia que le dispensa el público de esta capital, a pesar de no haber percibido de la que ha abandonado Mr. Bernard ninguna cantidad, no puede menos de respetar los abonos que actualmente existen, y conservará las localidades de los actuales abonados en los mismos términos y tiempo que se hallan en el día ${ }^{17}$.

La nueva empresa logró mantener dignamente el resto de la temporada, a pesar de la grave situación económica planteada, contratando nuevos actores y prolongando el tiempo inicialmente propuesto con 40 nuevas funciones de abono ${ }^{18}$. Además, el hecho de que esta empresa del Instituto fuera española y tuviera una compañía nacional, facilitó los contactos entre los actores de ambas nacionalidades, que llegaron a actuar juntos en las mismas funciones, aunque no en las mismas obras, con éxito de crítica y público. Esto se dio sobre todo en los beneficios. Así, Julián Romea, primer actor del Teatro de Lope de Vega, con parte de su compañía (Florencio Romea y las actrices Palma y Sampelayo), interpretó la comedia de Bretón Mi secretario y yo en el Teatro Francés el 22 de diciembre de 1853. La célebre bailarina Manuela Perea, la «Nena», y el director de coreografía Sr. Ruiz intervinieron con un baile español en la función del 29, en la que así mismo participó el tenor del Teatro Real, Malvezzi. En otra ocasión intervinieron los actores del Príncipe, Teodora Lamadrid y Arjona. Sin duda, además de las gestiones de la nueva empresa, pesaría la solidaridad profesional entre los artistas. El definitivo empeño de la nueva dirección, que vio reconocido con éxito de público y crítica, fue la contratación de la jovencísima actriz y bailarina Mlle. Montaland y de su padre, también actor y director de escena. Céline Montaland ya había tenido fortuna en los escenarios de Francia y otros países y tendría con posterioridad una carrera exitosa que la llevó a la Comedie Française. Las reseñas de la prensa madrileña son elogiosas, hablando de su prematuro talento:

porque prodigio puede llamarse a esa graciosísima artista que declama con rara inteligencia, canta con gusto y sentimiento, y baila con maestría y soltura, y domina en fin la escena con pasmosa facilidad, como solo es dado hacerlo a los más consumados actores ${ }^{19}$.

A ella se le atribuye el renovado interés por el Teatro Francés, muy decaído tras las experiencias de Daiglemont y Bernard.

Como dijimos, en la temporada 1854-1855 no hubo Teatro Francés en Madrid, sin duda por la inestable situación política española. En las dos siguientes, se asentó en el Teatro Lope de Vega con dos buenas compa-

17 Ídem, 9 de noviembre de 1853.

18 Ídem, 11 de diciembre de 1853.

19 Ídem, 19 de enero de 1854. 
ñías que no vieron reconocido su mérito con la asistencia numerosa del público, según la prensa. Se habían introducido grandes mejoras en el local y el conjunto de actores de ambos años resultó agradable y homogéneo. Siguieron también las buenas relaciones con compañías españolas, sobre todo con las que actuaban en el Circo y en el Príncipe ${ }^{20}$.

Desde la temporada 1857-1858 hasta la de 1860-1861, el Teatro Francés se asentó en el coliseo de Variedades ${ }^{21}$. El empresario fue, en todo este período, Mr. Coutourier, que reunió buenas compañías entre las que no escaseaban algunos nombres suficientemente conocidos en los teatros parisinos, como la primera actriz del género cómico del Variedades de la capital francesa, Mlle. Scriwaneck, o el primer actor y director de escena Victor Roger. También volvió la aún joven Céline Montaland acompañada de su padre, reverdeciendo los éxitos de su primera estancia.

En la temporada 1859-1860, la empresa propició primero la actuación de la compañía de la célebre actriz italiana Ristori, que procedía del Real y que comenzó sus funciones en el Teatro Francés el 25 de diciembre. Posteriormente, acogió una compañía de artistas zuavos a partir del 19 de enero. La compañía regular debutaría el 28 de enero y será considerada una de las mejores de los diez años.

En la última de las temporadas de existencia del Teatro Francés en Madrid se dio una anécdota que habla fundamentalmente de las diferencias en el trabajo actoral de las compañías españolas y las francesas y de cómo se recibía esto en el público. El 23 de abril de 1861, la troupe gala participa, en uno de esos intercambios de los que hemos hablado, en el beneficio de la dirección del Teatro del Circo y su ejecución queda reducida en la prensa a un elemento que sorprendió a los espectadores:

La compañía francesa, representada allí por los actores más caracterizados, tuvo asimismo una muy simpática acogida, si bien el pudoroso público de las galerías, recibió con cierta extraña alarma, la demostración oscular que es tan inocente como usual en la escena francesa: no es extraño, porque aquí andamos muy atrasados en las aplicaciones del sistema libre-cambista ${ }^{22}$.

La anécdota del beso en escena nos remite a una de las facetas vistas por Eugenio de Ochoa en su artículo de 1851. La sorpresa de los espectadores del Circo, comentada graciosamente por el crítico, nos explica una de las características de las compañías francesas especializadas en el

${ }^{20}$ La temporada 1855-1856 comenzó el $1^{\circ}$ de diciembre y terminó el 27 de abril. La siguiente, se inició el 17 de octubre de 1856 y finalizó el 26 de enero de 1857, fecha en la que la troupe marchó hacia Barcelona para dar algunas representaciones.

${ }^{21}$ La de 1857-1858 comenzó el 4 de enero de 1858 y terminó el 31 de mayo. La siguiente se inició el 23 de octubre y finalizó el 9 de junio. La de 1859-1860 se alargó, según circunstancias que comentamos en el texto, desde el 25 de diciembre de 1859 hasta el 27 de mayo. La última se inició el 2 de marzo de 1861 y concluyó el 31 de mayo.

${ }^{22}$ La Iberia, 24 de abril de 1861. 
vaudeville: lo picante de las insinuaciones y situaciones que llamaba tanto la atención del público y censuraron durante los primeros años de estancia del Teatro Francés en Madrid los críticos moralistas. Más aun, por primera vez, los aficionados madrileños al teatro y los actores españoles que no tenían la posibilidad de viajar a París podían ver otras formas de ejecutar las obras y especialmente las piezas cómicas en las que se basaban esencialmente estas funciones y que tanta repercusión tuvieron en la evolución del teatro español del siglo XIX.

Como hemos dicho, la llegada a España, a comienzos de la década de los 50, de compañías francesas que representaban en francés y el interés inmediato que despertaron se debió, en buena medida, a la novedad que para el público español suponían sus espectáculos teatrales y, en especial, dos facetas sumadas sobre la escena: por un lado, la forma de representar de estos actores; por otro, los, textos en la versión original. En su repertorio dramático ofrecían variedad de géneros: comedias, dramas, vodeviles, óperas, operetas, etc. Sin embargo, pronto se pudo comprobar que, de todas las modalidades, la que más atrajo al público madrileño era el vodevil, tanto por ser algo diferente a lo que se daba en la escena española como por «la picante jocosidad de la mayor parte de sus producciones» y «la malicia y libre desenfado con que varios actores ejecutaban sus papeles» ${ }^{23}$.

En el período estudiado se pusieron en escena cerca de cuatrocientos títulos. La gran mayoría eran piezas en un acto. Entre los distintos géneros destacan sobremanera los vodeviles y la comedia-vodevil. El ligero vaudeville, divertido y picante era la auténtica atracción. Era este un género prácticamente inexistente en el teatro español y de larga tradición en el francés.

Conviene dedicar unas líneas para considerar mejor la novedad que significó la representación del vaudeville francés en lengua original por actores de esa nacionalidad en los locales madrileños. Con anterioridad a 1851, el género sólo era conocido en su integridad —es decir, como espectáculo escénico completo- por los que habían viajado a París y asistido allí a representaciones teatrales. Aunque desde muy pronto hay noticias sobre el vaudeville, incluso en su fórmula primitiva ${ }^{24}$, será a partir de Scribe y de su círculo cuando más interese como pieza escénica a los aficionados españoles. Sin embargo, en su primera aparición en los teatros madrileños, el vaudeville no responde a la modalidad tal y como podía conocerla el público francés, sino al arreglo español del texto, prescindiendo de la música, es decir, a su conversión en una comedia breve. Estas traduccio-

${ }^{23}$ Ídem, 15 de diciembre de 1855 y 5 de enero de 1856.

${ }^{24}$ Así lo encontramos, por ejemplo, en el «Diálogo entre el autor y Boileau», soneto de Juan Bautista ARRIAZA, en uno de cuyos versos se lee: «y en donde hay vodevil pon seguidillas» (Poesías líricas, I, Madrid, Imprenta Real, 1829). 
nes suponen la aparición de una fórmula distinta al vaudeville, la comedia en uno o dos actos, que tendrá una larga trayectoria posterior en la escena española.

Bretón de los Herreros, uno de los primeros y más importantes traductores del vaudeville, al que definía como «ciertos dramas jocosos de poca duración (especie de sainetes), en cuyo diálogo se mezclaban coplillas epigramáticas» ${ }^{25}$, tuvo de él una opinión muy favorable, muy superior a la que le merecía el ya agotado sainete tradicional, proponiéndolo como fórmula más moderna:

El Vaudeville francés, tesoro de agudezas, preciso es hacerle esta justicia, nos ha suministrado y suministra todos los días juguetes dramáticos muy lindos, que sin faltar al pudor y a la buena crianza divierten al espectador más que el mejor sainete, cuando se sabe acomodarlos a nuestra escena. Muchas de estas piezas podríamos citar que cada vez oye el público con más agrado, concediendo a los autores más lisonjeros aplausos que los que pueden arrancar al patio malgastando su ingenio en representar sandeces y cerriladas ${ }^{26}$.

En uno de sus artículos más conocidos de crítica teatral, Larra abordó el fenómeno de las traducciones del teatro francés y, de manera particular, de la introducción del vaudeville y de su trascendencia. Recordemos que él mismo ya por entonces reunía la doble faceta de traductor de estos textos y de crítico teatral ${ }^{27}$. Se refirió a él en estos términos:

El vaudeville, género de composición dramática puramente francés, fue una mina inagotable; género complejo, verdadero melodrama en miniatura, así participa de la ópera como de la comedia; hijo de las costumbres francesas, bástale su diálogo diestramente manejado y erizado de puntas epigramáticas;

${ }^{25}$ Manuel Bretón de los Herreros, «De los sainetes», en J. M. DíEz TABOAda y J. M. RozAs (eds.), Bretón de los Herreros. Obra dispersa. I. El Correo Literario y Mercantil, Logroño, 1965, p. 286.

${ }^{26}$ Ídem, p. 171. Bretón tradujo su primer vodevil de un original de Scribe con el título de Un paseo a Bedlam, o la reconciliación por la locura, representado en Madrid por primera vez en julio de 1828. M.A. Muro dice al respecto que Bretón «eligió una obra de Scribe que venía a ser un prototipo de lo deseable en el vaudeville: diversión conseguida con procedimientos acertados y con buen gusto» (M. BRETóN DE LOS HERREROS, Obra selecta. II. Teatro breve original y traducido. Teatro refundido, ed. de M. A. Muro, Logroño, Universidad de La Rioja, 1999, p. 76). La traducción de Bretón tuvo gran éxito y siguió representándose con asiduidad, al menos, hasta la década de los sesenta.

${ }^{27}$ Bajo el pseudónimo de Ramón Arriala, Larra había traducido varias obras del teatro francés con anterioridad, entre las que figuran algunas comedias de Scribe. Véanse las editadas por Leonardo ROMERO TOBAR en Mariano José de LARRA, Textos teatrales inéditos, Madrid, CSIC, 1991. En concreto, sobre la gran presencia de textos arreglados de Scribe, Larra, en su artículo «Una primera representación», los define casi como una modalidad aparte y escribe: «Hay la piececita de costumbres sin costumbres, traducción de Scribe, insulsa a veces, graciosita a ratos, ingeniosa por aquí y por allí» (Revista Mensajero, 3 de abril de 1835). 


\begin{abstract}
esto, y algunos casos monótonos que giran casi siempre sobre temas semejantes, bastan a adornar una idea estéril que pocas veces produce más de una o dos escenas medianamente cómicas. El pueblo francés, tan cantor como mal músico, se paga de eso, y tiene razón, porque no le da más importancia que la que tiene, y porque rico el teatro de cómicos excelentes, el juego mímico y la perfección del arte prestan interés del otro lado de los Pirineos a la composición más desnuda de mérito y de originalidad ${ }^{28}$.
\end{abstract}

Larra señala que el vaudeville, arreglado a la escena española, se desnaturaliza al «perder la mitad de su ser, es decir, la música» y sólo puede admitirse, dado que no se acomoda a las costumbres españolas ${ }^{29}$ ni al gusto del público, «en cuanto a comedia y a cuenta de comedias», es decir, sólo tienen éxito aquellos cuyo argumento está mejor desarrollado y su enredo tiene alguna sustancia, pero sin pretender sustentar nunca una función completa. Los empresarios trataron de sustituir con esta nueva modalidad a los viejos sainetes que ya no eran atractivos ni para los escritores ni para los espectadores. La intención de desplazar al sainete merece los elogios de Larra, puesto que lo consideraba un género arcaico e inadecuado para el teatro del momento ${ }^{30}$. Esta polémica, cuyo objetivo era la sustitución del sainete por la nueva modalidad cómica nacida sobre todo de los arreglos a partir de los vodeviles de Scribe y otros autores, se continúa en el tiempo y encuentra otro mantenedor en Ventura García Escobar, quien publicó una serie de tres artículos en La Luneta en 1848 con el título de «Los Sainetes». En ellos proclamaba esta modalidad como anticuada y contraria a la moral y al arte de la época y propugnaba su sustitución:

La sustitución de los Sainetes son las piezas del género cómico, ligeras e insinuantes, decorosas y festivas. En ellas se desenvuelve cualquiera idea filosófica, social, o moral bajo la fórmula del gracejo, la superficialidad y la sencillez. El pueblo con ellas puede reír, aprender, y morigerarse. Porque con una

\footnotetext{
${ }^{28}$ Este fragmento pertenece al artículo «De las traducciones», El Español (11 de marzo de 1836).

${ }^{29}$ Este.apunte de Larra, en el que resalta la falta de aclimatación del género, se convertirá en crítica con tintes nacionalistas en otros autores. De este modo, Juan Valera sólo pone un reparo a una brillante velada en la casa de los duques de Medinaceli, a la que asistió la Reina: «Sólo sentimos que siendo tan buenas artistas las señoras duquesas de Medinaceli y marquesa de Villaseca y las señoritas de Torrejón, Paz y Álvarez de Toledo, y teniendo además estas artistas apellidos tan castizos, tan españoles y tan ilustres, no desechen los vaudevilles traducidos del francés y no se empeñen en representar siempre originales de nuestros poetas contemporáneos o de los antiguos. (...) a nosotros nos pesaba de que una compañía dramática cuyos individuos se honran con los más gloriosos, antiguos y venerandos de nuestra historia, no representasen obras originales, dando quizá a entender a los ignorantes de nuestra literatura que no las tenemos buenas» (J. VALERA, Obras completas, III, Madrid, Aguilar, 1958, p. 1276).

${ }^{30}$ Años antes, R. de MESONERo ROMANOS había intervenido en la polémica quejándose del excesivo número de traducciones («De las traducciones», en El Correo Literario y Mercantil, 19 de noviembre de 1828).
} 
forma fácil y adaptable a su comprensión y estado, se le inocula un principio sano, y próbido; así como a los niños, bajo el oropel de la píldora, se les propina una substancia, que proporciona el desarrollo y la salud. La comedia urbana llena además todas las condiciones del arte y del siglo. Sus delicados chistes nos solazan, al paso que las torpes bufonadas de los Sainetes nos abruman. $\mathrm{Y}$ al tipo del gracioso del antiguo régimen, licencioso, chocarrero e inculto, ha reemplazado ya el gracioso cómico, que no está en divorcio con la cortesía, el decoro y el don de bien decir; lo cual constituye la gracia verdaderamente artística y teatral ${ }^{31}$.

Sin embargo, señala Larra siguiendo con su artículo, en la mayoría de las traducciones no se cuidó de nacionalizar el texto, lo que implicó que fueran piezas de corta vida, con un éxito efímero. De ellos sólo quedaron los «que tenían más analogía con nuestras costumbres o aquellos en que una idea verdaderamente cómica y original se hallaba bien adoptada y desarrollada por un traductor hábil», como era el caso de Bretón de los Herreros o Ventura de la Vega.

Esta fórmula señalada por Larra fue el vehículo de conocimiento del vaudeville para todos los espectadores españoles que no tuvieron la oportunidad de viajar a Francia para asistir allí a las representaciones de un género que, por lo demás, hacía furor en París ${ }^{32}$. Así se puede explicar más adecuadamente la radical novedad que supuso la presencia en Madrid de las compañías francesas a partir de 1851.

Las líneas anteriores también justifican, en gran medida, el predominio del vodevil sobre cualquiera de las otras modalidades representadas en el Teatro Francés de Madrid. Más de la mitad de las piezas que se ejecutaron en su versión original corresponden al vodevil o bien a la comedia-vodevil. Es lógico si pensamos que era algo que no existía en el repertorio de las compañías españolas, diferente a cualquiera de las modalidades que se presentaban en el panorama del teatro español, aunque tuviera similitudes con algunas, como se encargaron de indicar varios críticos y teóricos ${ }^{33}$. En un

\footnotetext{
31 Ventura García Escobar, «Los Sainetes», en La Luneta, 1848, n. ${ }^{\circ} 19$, p. 138.

${ }^{32}$ De ahí la sorpresa de algunos viajeros cuando asisten a la representación de vodeviles en la capital francesa: «En cuanto al género de estas composiciones, nada diremos por ser harto conocidas de nuestro público, y únicamente halla de extraño en ellas el extranjero la indiscreta mezcla de diálogos hablados y coplillas cantadas, lo cual, además de absurdo, es ridículo en boca de actores nada propios para el canto» (R. de MESONERo RomAnOS, Recuerdos de viaje por Francia y Bélgica en 1840-1841, Madrid, Imprenta de M. de Burgos, 1841, p. 211).

${ }^{33}$ M. MiLÁ y FonTANALS lo aproxima a la zarzuela y la tonadilla españolas, en las que se «alternan la declamación y el canto» («Poesía dramática o activa. Artículo primero. De la poesía dramática en general», en Compendio de arte poética, Barcelona, Imprenta de D. J. de Grau, 1844). M. DE LA REvILla viene a identificarlo con un «sainete en que los personajes cantan canciones breves» (Lección LII de sus Principios generales de literatura e historia de la literatura española, Madrid, Librería de Francisco Iravedra, 1877).
} 
momento en que el público se cansaba rápidamente de los títulos y los empresarios se veían forzados a renovar continuamente los carteles, en una situación en la que la sociedad madrileña aspiraba a parecerse a la parisina del Tercer Imperio, en cuyo modelo se miraba cada vez más, y en un contexto teatral en el que ya el romanticismo se agotaba y todavía se hallaban en formación las líneas principales de la estética posterior, el Teatro Francés vino a llenar un hueco no cubierto por el teatro nacional, con una modalidad que respondía a la perfección a las exigencias de diversión de un público ya muy aburguesado, tanto en su forma de vida como en su mentalidad y que se había hecho casi en exclusiva con los principales locales teatrales. En algunos sectores, la moda del vodevil se convirtió en una demostración de buen tono y se esgrimía como una cuestión de modernidad para separarse de lo tradicional español. Así, el ya citado Domingo Faustino Sarmiento, llegado a Madrid tras una estancia en Europa, después de insistir en el atraso de la civilización española y, como lógica consecuencia, de la literatura del país en general y del teatro en particular, afirmaba que «un vaudeville me causa mayores sensaciones que todo el repertorio español antiguo y moderno» ${ }^{34}$. Refiriéndose a este hecho, Juan Valera se lamentaba de que «no pocos españoles, principalmente los que viajan y leen, han acabado por formar sobre su patria un concepto tan malo como los mismos extranjeros», como un sujeto elegante que conoce «y que condena por de mal tono y cursis los chistes de Bretón y se extasía y califica de elegantísimos los más sucios equívocos del Palais Royal, o del más necio y obsceno vaudeville» ${ }^{35}$.

La gran mayoría de los vaudevilles representados por las compañías francesas que pasaron por Madrid eran textos de uno o dos actos, pero también los hubo, muy pocos, de hasta cinco, siendo el más famoso de estos últimos Les folies dramatiques de Dumanoir y Clairville. Con más de diez representaciones, además del citado, hemos encontrado los siguientes títulos: La corde sensible, Les premières armes de Richelieu, Una fille terrible, La chanoinesse, La meunière de Marly, L'amour, qué qu' c'est qu' ça?, Le mari de la veuve, La protegée, Riche d'amour, Ce que la femme veut..., Embrassons-nous, Folleville, Un monsieur et une dame, Le commis et la grisette, La ferme de la Primerose, La fille de Dominique, Jeanne Mathieu, Margot, Tambour battant y Un changement de main.

A pesar de la buena recepción de que gozaron muchos de estos, los comentarios críticos, por lo general, no fueron más allá en sus elogios de señalar que eran piezas graciosas, divertidas, ingeniosas, algo picantes, etc., lo que, las más de las veces, les disculpaba de la ausencia de otros méritos. No obstante, en algunos casos, la insustancialidad de la obrita era tal

${ }^{34}$ Viajes en Europa, África i América (1845-1847), op. cit., p. 175.

${ }^{35}$ Historia y Política, en Obras Completas, III, op. cit., p. 749. 
que no se pasaba por alto. A propósito de la representación del vodevil en un acto Zamore et Giroflée, Juan de la Rosa decía que tal «especie de superficialidad picaresca, no tiene otro mérito que el que una cantatriz ejecute algunos pasos de baile algo libre, con tanto donaire como descaro, y que fueron tres veces repetidos entre los bravos y las palmadas de la gente comme il faut. Verdaderamente no comprendemos este entusiasmo que tanto contrasta con nuestras buenas costumbres y con lo que de decoro y conveniencias sociales se debe siempre a un público tan respetable como el de la capital de España» ${ }^{36}$. Son muy significativas estas palabras de un crítico que procede del sector del liberalismo progresista, puesto que una de las alusiones más frecuentes de las reseñas aparecidas en la prensa durante la vida del Teatro Francés fue precisamente la inmoralidad de alguna de las producciones, lo que alarmaba, al menos en apariencia, a un sector del público burgués del momento ${ }^{37}$. La crítica al respecto la encontramos ya en un artículo aparecido en el Diario Oficial de Avisos a las pocas fechas de las primeras funciones dadas en 1851:

A propósito de este teatro, la Gaceta de ayer trae las siguientes líneas con las que estamos conformes: «Algunos abonados en el teatro de la Cruz, nos ruegan manifestemos a la empresa del mismo su deseo de que no se pongan en escena comedias que repugnen a las buenas costumbres y ofendan la sana moral. Felizmente en España no tenemos aún la despreocupación de nuestros vecinos de allende el Pirineo, que tantos males les ha producido y les está produciendo; y aunque una parte del auditorio, compuesta acaso de extranjeros, aplauda y celebre chistes y frases de doble sentido, la mayoría del público, la mayoría sensata e ilustrada, deplora que se le den obras como Indiana y Charlemagne, Les premiéres armes de Richelieu y le Caporal y la Payse, pertenecientes todas al repertorio del Palais Royal de París, el teatro más desvergonzado, el más licencioso de cuantos hay allí, y a donde no asiste nunca ninguna señora que se respete.

Días pasados hicimos una ligera indicación sobre el particular que, siendo desatendida, nos vemos en la necesidad de explanar hoy.

Crea la empresa del coliseo de la Cruz, que comprende muy mal sus intereses y su porvenir, no dando justa y grande importancia a la parte moral de sus espectáculos, pues nos consta que hay familias, y abonados entre ellas, que no asisten a la primera representación de una comedia hasta saber si pueden consentir que sus hijas la vean sin ruborizarse.

Obras como Mercadet, Genevieve, Les premiers amours, como otras tantas en fin que entre muchas de peligrosa tendencia se encuentran todavía, son las que deben dársenos: en los repertorios del Gimnasio, del Odeón, del Vaudeville, y especialmente del Teatro Francés de la calle de Richelieu, es donde han de buscarse, y no en los del Palais Royal y Varietés.

\footnotetext{
${ }^{36}$ La Iberia, 13 de febrero de 1856.

${ }^{37}$ Decimos en apariencia, puesto que en varias referencias periodísticas se insistía en que, precisamente, uno de los atractivos de este teatro era su carácter picante. Lo que venía a cuestionarse era su condición de espectáculo familiar.
} 
Si se nos dice que no faltan espectadores ni aplausos para tales engendros, contestaremos que por desgracia tampoco faltan gentes que se extasíen con la detestable novela de Crebillon El Sofá, ni con las de Pigaul Lubren y Paul de Kock; y sin embargo los hombres de buen gusto literario y la sana moral las reprueban y condenan de consuno.

Hemos sido y seguiremos siendo severos, porque la cuestión lo merece; y porque dispuestos a proteger a todas las empresas teatrales, lo estamos también a no consentir que ninguna se extravíe ni traspasa los justos límites de la decencia y del decoro ${ }^{38}$.

En algún caso llegó a darse la prohibición, por considerarla inmoral la autoridad gubernativa, de alguna pieza ya representada, como sucedió en diciembre de 1852 con el vodevil Sous clef:

\begin{abstract}
Nosotros, que en la temporada anterior anatematizamos las piezas del repertorio francés que nos parecieron perniciosas para nuestro público por su inmoralidad y tendencias, no podemos menos de condenar severamente el vaudeville Sous clef, que, estrenado el domingo con general reprobación fue prohibido al día siguiente con mucha razón por la Autoridad. Sentimos que Mr. Daiglemont haya dado este nuevo mal paso, y que se hiciese cómplice de él Mlle. Michaux, actriz graciosa e inteligente, a quien el público había favorecido con sus aplausos ${ }^{39}$.
\end{abstract}

Además de exitosos vodeviles, las compañías de teatro francés traían en su repertorio un buen número de comedias. Abundaron las escritas en un acto, de autores muy conocidos. Las hubo que incluso llegaron a rivalizar en reposiciones con los más aplaudidos vodeviles. Teniendo en cuenta que muchas de ellas incluían también canciones y cuplés, cabe pensar que la diferencia entre ambos géneros debía de ser casi inapreciable. Entre las de un acto, las más repetidas, con 17 representaciones, fueron Brutus lâche César de Rosier y Le piano de Berthe de Barière y Lorin, ambas con canciones, y le siguen, por orden descendente, con un mínimo de 10 representaciones, Le caporal et la payse, Le misanthrope et l'auvergnat, Le code des femmes, Livre III, chapitre I, La joie fait peur, Une mauvaise nuit est bientôt passée, Le chapeau d'un horloger, Pas de fumée sans feu, Un caprice, Le Cachemire vert! y Un monsieur qui prend la mouche. Se vieron muchas menos comedias en dos actos y se observa que las más representadas (Le chevalier du Guet de Lockroy, Les droits de l'homme de Prémaray y Une jeunesse oragause de Desnoyer) no eran obras de reciente estreno en París.

En cuanto a las piezas de mayor extensión, sobresalen: Bataille de Dames de Scribe y Legouvé, Les femmes fortes de Sardou, Les saltimbanques de Dumersan y Varin y Valerie de Scribe y Mélesville, en 3 actos; La Niaise de Mazères, en 4 actos; y Le demi-monde y Un père prodigue

${ }^{38}$ Diario Oficial de Avisos de Madrid, 30 de noviembre de 1851.

${ }^{39}$ Gaceta de Madrid, 9 de diciembre de 1852. 
de Dumas hijo, Tartuffe de Molière, Les effrontés de Augier, L'honneur et l'argent de Ponsard y Mademoiselle de Belle-Isle de Dumas, en 5 actos.

El drama tuvo, cuantitativamente, escasa presencia en el Teatro Francés. De los doce que hemos registrado, seis no pasaron de una o dos representaciones. Algunos de estos eran ya conocidos por haber sido traducidos y llevados a escena con anterioridad, como es el caso de Antony de Dumas $^{40}$ o Un duel sous le cardinal de Richelieu de Lockroy y Badon ${ }^{41}$. Curiosamente, Antony, tan célebre y controvertido en su día ${ }^{42}$, ahora apenas interesó. Según se dice en la Gaceta de Madrid, este drama «no satisface ya el gusto de la época ni las exigencias del drama moderno» ${ }^{43}$.

Los dramas más veces representados fueron: La dame aux camélias de Dumas hijo (5 veces); Adrienne Lecouvreur de Scribe y Legouvé, Le chef d'oeuvre inconnu de Lafont, Dalila de Feuillet y Les filles de Marbre de Barrière y Lambert-Thiboust (4 veces). 'Es interesante la reseña que hizo Juan de la Rosa en La Iberia sobre la esmerada representación del dramacomedia La dame aux camélias, en 5 actos, en prosa y con canciones, en la que, a pesar de poner de manifiesto la falta de moralidad de la que, a su juicio, adolecía la obra, reconocía sus valores artísticos:

\begin{abstract}
Los actores que tomaron en él parte rivalizaron a porfía en la ejecución de sus respectivos papeles; así Mlle. Divay en el de Nanine, como Mr. Dorval en el de Armand, y Mr. Stalislas en el de Gaston; empero, distinguiéndose sobre todos ellos Mlle. Blainville en role trés dificil, de Margarita Gautier. Del mérito de este drama, escaso de buena enseñanza y de moralidad, aunque escrito con la maestría que a su autor es propia, diremos que por muchos conceptos no le creemos digno de ser representado ante la escogida sociedad que concurre a este teatro ${ }^{44}$.
\end{abstract}

Adriana de Lecouvreur, calificada como comedia-drama, en cinco actos, era también una obra conocida en el teatro español, gracias al arreglo realizado por Ramón de Navarrete un año después de su estreno, el 14 de abril de 1849, en el Théâtre de la République de París ${ }^{45}$.

Aunque de algunas de estas obras ya se habían hecho versiones españolas, los espectadores tenían ahora la oportunidad de conocerlas tal como se representaban en su país de origen. Por ejemplo, una de las de más éxito,

\footnotetext{
${ }^{40}$ Fue traducido por Eugenio de Ochoa con el mismo título, y se estrenó en el Teatro del Príncipe el 19 de junio de 1836.

${ }^{41}$ Arreglado por Larra con el título de Un desafío. Se estrenó en el Teatro de la Cruz el 26 de noviembre de 1834 . Véase la reciente edición de M. ${ }^{a}$ Isabel JiMÉNEZ MoRAles de M. J. de LARRA, Un desafio, Madrid, Instituto de Estudios Madrileños, 1998.

${ }^{42}$ Larra le dedicó dos artículos que aparecieron en El Español (23 y 25 de junio de 1836).

${ }^{43}$ Gaceta de Madrid, 28 de enero de 1852.

${ }^{44}$ La Iberia, 21 de abril de 1861.

45 La vida de esta actriz, la más famosa de su tiempo (1692-1730), inspiró también la ópera de Francesco Cilea Adriana Lecouvreur.
} 
la comedia-vodevil en un acto titulada Brutus lâche César ${ }^{46}$, representada por primera vez en Madrid en noviembre de 1851, ya tenía una traducción española, El perro de centinela, estrenada dos años antes. Se podrían citar otras muchas, entre ellas: Les crochets du père Martin (El tío Martín o la honradez, traducida en 1859 por J.F. Gil y Baus); Les fées de Paris (Otra casa con dos puertas, en 1842, por V. de la Vega); La Fiammina (Dos artistas, en 1857, por A. Iznardi); Le mariage de raison (El casamiento por convicción, en 1828, por M.Bretón de los Herreros); Pattes de mouche (Historia de una carta, en 1860, por J.F. Gil y Baus); Les premières armes de Richelieu ( Es un niño!, en 1843, por Hartzenbusch y García Doncel ); Riche d'amour (Con amor y sin dinero, en 1846, por R. Navarrete); La soeur de Jocrisse (Las gracias de Gedeón, en 1844, por R. Navarrete); y Une femme qui se jette par la fenêtre (La pena del Talión, en 1847, por R. Navarrete). Si comparamos estos datos con los que ofrecemos en la lista final de obras francesas del apéndice, observamos que la fecha de la traducción española era muy cercana al estreno de la original en Francia y que la representación en francés en España era casi siempre posterior a la de la traducción.

Por otro lado, algunas obras de mucho éxito en París no tardaron en presentarse en Madrid, en el período analizado de 1851 a 1861. La comedia de costumbres Les petites mains, de Labiche y Martin, se estrenó en España el 31 de enero de 1860, dos meses después que en París (28 de noviembre de 1859). De igual modo, la mejor comedia de la temporada de 1858, Le fils naturel, de A. Dumas (hijo), se representó por primera vez en París el 16 enero y en el mismo año en Madrid, el 23 de marzo, y su traducción española (El hijo natural) el 13 de marzo ${ }^{47}$. Entre estas las hubo que revalidaron en España la fama que las precedía, como pone de manifiesto la reseña que publicó La Iberia a raíz del estreno de Les Effrontés:

\begin{abstract}
Anoche nos convencimos de lo justificados que son los elogios tributados en París a Mr. Emilio Augier por su última producción, digna en efecto de la mayor alabanza. La escogida sociedad que llenaba la sala de la calle de la Magdalena, escuchó con grande silencio la esmerada representación de Les Effrontés, magnífica comedia de costumbres, en cinco actos y un chef d'ouvre, del nuevo repertorio francés, que, con sobrado motivo, está ahora haciendo furor en la capital del vecino Imperio. El autor no ha desmentido en esta obra el merecido crédito de su elegante pluma. Argumento natural y caracteres verídicos, sostienen el interés del espectador hasta el fin de la comedia. Momentos hay en los cuales el público, más que en un teatro, cree hallarse presenciando ciertas escenas familiares de que tanto abunda la sociedad moderna. La crítica
\end{abstract}

\footnotetext{
${ }^{46}$ De Joseph-Bernard Rosier. Estrenada en el Gymnase-dramatique de París el 2 de junio de 1849 .

${ }^{47}$ Se representó en el Teatro Novedades y se mantuvo en cartel hasta el 5 de abril. Véase I. VALLEJO y P. OJEDA, El teatro en Madrid a mediados del siglo XIX. Cartelera teatral (1854-1864), op. cit.
} 
severa que encierra esta bellísima composición de Mr. Augier contra la nueva aristocracia del dinero, no puede ser más completa.

En general debe asegurarse que la ejecución fue buena pues los actores recitaron con naturalidad sus respectivos papeles, sobresaliendo Mlles. Periga, en el de marqués d'Auberid, y Mlle. de Brunel en el de Clemence, las cuales fueron muy aplaudidas, así como Mr. Stanislas en el interesante role de Henri (fils. de Mr. Charrier) que con tanto acierto desempeñó.

Aconsejamos a aquellos de nuestros lectores que conocen y cultivan el idioma de Racine y de Moliere, acudan a admirar esta comedia, muy seguros de que saldrán satisfechos, así de su mérito como de su ejecución, pasando una soirée muy agradable.

Al público madrileño que asistía al Teatro Francés, como ya hemos dicho, le gustaban las novedades $y$, por el contrario, le suscitaban poco interés las piezas ya conocidas. No obstante, echaban en falta en el repertorio de las compañías la presencia de los clásicos. De Molière sólo se representaron tres obras: Le Tartuffe $\left(8\right.$ veces) ${ }^{48}$, Le Dépit amoureux (2 veces) y Le Malade imaginaire (una vez).

Las compañías francesas montaron también algunas obras líricas. Fueron muy pocas, un total de siete, entre óperas en 3 actos (Les mousquetaires de la Reine y La dame blanche), una ópera bufa en un acto (Le rendezvous bourgeois), operetas en un acto (Les pantins de Violette, La rose de Saint-Flour y L'île de Calypso) y un «disparate musical» con baile (TrombAl-ca-zar). La explicación de esta relativa desproporción entre estos espectáculos y los vodeviles nos viene dada por algunos comentarios críticos a propósito de la representación de las dos óperas. Jules Bernard, director del Teatro Francés, que había iniciado la temporada 1853-1854 con Les mousquetaires de la Reine, en el ya citado comunicado remitido al Heral$d o$, reconocía que no había estado acertado, dándose cuenta de que lo que verdaderamente esperaba el público eran los vodeviles, que tanto éxito habían tenido en las temporadas anteriores, y se comprometía a «presentar pronto obras de menores pretensiones y de más fácil ejecución». Días más tarde, después de la representación de la segunda ópera (La dame blanche), encontramos en la Gaceta de Madrid una reseña en la que se dice que la compañía lírica del Teatro Francés «es muy mediana», mientras que la de vodevil es excelente ${ }^{49}$. No es de extrañar que esto ocurriera así, teniendo en cuenta que Madrid contaba con teatros y compañías dedicados exclusivamente al género lírico y con un público que ya era asiduo del Real o del Circo. Sin embargo, sí que tuvieron relativo éxito las operetas, piezas

\footnotetext{
${ }^{48}$ En la temporada de 1852 tuvo 6 representaciones sucesivas y se ejecutaron «a telón corrido como en el Teatro Francés de París» (Gaceta de Madrid, 2 de noviembre de 1852).

49 Ídem, 24 de octubre de 1853.
} 
más ligeras y más en consonancia con las otras obras que ofrecía el Teatro Francés. La primera que se puso en escena en Madrid fue La Rose de Saint-Flour, del gran maestro Offenbach, verdadero creador el género, sólo cinco meses después de su estreno el 11 de junio de 1856 en los BouffesParisiens, y se repuso en seis ocasiones desde el 14 de noviembre hasta el 3 de enero del año siguiente.

La nómina de autores teatrales franceses cuyas obras fueron representadas en versión original en nuestro país durante el período analizado es amplísima: supera los doscientos nombres. Conviene hacer, sin embargo, algunas precisiones al respecto. La mayoría de las piezas fueron escritas en colaboración y más de la mitad de los autores tienen sólo una obra. El autor con mayor número de títulos en la cartelera fue Scribe, con treinta y tres. Le siguen, con diez o más: Labiche (29), Dumanoir (28), Marc-Michel (27), Bayard (26), Mélesville (18), Lambert-Thiboust (16), Clairville y Duvert (14), Barrière (13), Decourcelle (12), Varin (11), y Lauzanne, Anicet-Bourgeois y Xavier (10). Por número de representaciones de todas sus obras, encabeza la lista Dumanoir con ciento cincuenta y tres, y le siguen, con más de cien, Labiche (150), Scribe (141), Bayard (132), MarcMichel (114) y Clairville (102).

Ya hemos comentado que la gran mayoría de las obras francesas que se vieron en Madrid eran del tipo de vodevil o comedia-vodevil. No es de extrañar que las compañías eligieran las de los principales cultivadores del género. Eugène Scribe (1791-1861) fue el gran renovador de esta modalidad. Partiendo del esquema tradicional, consiguió una fórmula válida que sirvió para avivar el interés del público por el vodevil. Henri Gidel ha señalado lo esencial de su aportación, la inclusión de elementos propios de la comedia clásica:

\begin{abstract}
Il transfère donc dans le vaudeville la technique d'intrigue dont il trouve le modèle dans la comédie classique ou néo-clasique, celle de Corneille, celle de Beaumarchais, celle dont Picard a fait la théorie dans Les Marionettes (1806). En particulier, il apprend à exploiter brillamment toutes les ressources du quiproquo, à ménager l'intérêt en piquant la curiosité du public par un jeu savant de préparations, à organiser un «suspens». Bref, il apporte un second souffle au vaudeville, qui s'épuisait dans la répétition mécanique des mêmes formules ${ }^{50}$.
\end{abstract}

Según Gidel, su influencia se dejó notar no sólo entre otros «vodevilistas», muchos de cuales fueron sus colaboradores y luego continuadores, sino también sobre autores como Augier y Dumas hijo. Como libretista de óperas, Scribe colaboró con Delavigne en Roberto il Diavolo, de

${ }^{50}$ Véase H. Gidel, Le vaudeville, Paris, Presses Universitaires de France, 1986, p. 50. 
Meyerbeer, y con Duveiryer en Les vêpres siciliennes, de Verdi, obras que también se montaron en el Teatro Real de Madrid por los años cincuenta.

De las setecientas veintitrés funciones del Teatro Francés anunciadas en las carteleras de espectáculos de los periódicos de Madrid, desde la inaugural, del 5 de noviembre de 1851, hasta la última, el 31 de mayo de 1861, hemos extraído la relación de piezas que se representaron y que ofrecemos a continuación ${ }^{51}$. De cada título, ordenado alfabéticamente, se dan sus características, autor o autores y la fecha de primera representación en Francia (F:) y en España (E:).

\section{ABREVIATURAS UTILIZADAS}

$\begin{array}{llll}\text { a. } & \text { acto } & \text { m. } & \text { música [de] o músico/s } \\ \text { al. } & \text { alemán } & \text { mon. } & \text { monólogo } \\ \text { aprop. } & \text { apropósito } & \text { mus. } & \text { musical } \\ \text { b. } & \text { baile } & \text { óp. } & \text { ópera } \\ \text { c. } & \text { comedia } & \text { opta. } & \text { opereta } \\ \text { canc. } & \text { canción[es] } & \text { p. } & \text { parte } \\ \text { cdr. } & \text { cuadro } & \text { par. } & \text { parodia } \\ \text { cóm. } & \text { cómico/a } & \text { pról. } & \text { prólogo } \\ \text { cost. } & \text { [de] costumbres } & \text { pr. } & \text { prosa } \\ \text { disp. } & \text { disparate } & \text { prov. } & \text { proverbio } \\ \text { dr. } & \text { drama } & \text { pz. } & \text { pieza } \\ \text { esc. } & \text { escena } & \text { trad. } & \text { traducción, traductor } \\ \text { espt. } & \text { espectáculo } & \text { v. } & \text { verso } \\ \text { fant. fantasía/ fantástico/a } & \text { vod. } & \text { vodevil }\end{array}$

\section{RELACIÓN DE OBRAS}

À la Bastille.-vod. 1 a.; Xavier, Duvert y Lauzanne [F: 6/5/1850] [E: 3/1/1852] Adrienne Lecouvreur.-c.-dr. 5 a.; Scribe y Legouvé [F: 14/4/1849] [E: 2/3/1861] Affaire de la Rue de Lorucine, L'.-c. 1 a. con cuplés ; Labiche, M. Monnier y E. Martin [F: 26/3/1857] [E: 20/4/1858]

Affiche de Nanterre, l', ou le provincial à Paris.-pz. 1 a.; [E: 1/1/1853]

Ami François, L'.-c.-vod. 1 a.; Bourdois y Colliot [F: 19/10/1852] [E: 2/12/1858]

Amour à l'aveuglette, L'.-c.-vod. 1 a.; Mélesville y Xavier [F: 17/3/1851] [E: 5/11/ 1852]

Amour, qué qu' c'est qu'ça? L'.-vod. 1 a.; Clairville, Lambert-Thiboust y Delacour [F: 6/4/1853] [E: 2/12/1855]

${ }^{51}$ Hemos consultado los siguientes periódicos, contrastando los datos de la cartelera con las reseñas teatrales: Diario Oficial de Avisos de Madrid, La Ilustración, Gaceta de Madrid, La Iberia, El Estado, La Discusión y El Occidente. 
Amours de Cleopatre, Les.-c. 3 a. con cuplés; Marc-Michel y Delacourt [F: 5/4/1860] [E: 22/4/1861]

Anglaises pour rire, Les. - c. 1 a. con cuplés; Sewrin y Dumersan [F: 26/12/1814] [E: 28/2/1852]

Antony.-dr. 5 a. pr.; Dumas, A. [F: 3/5/1831] [E: 26/1/1852]

Article 213, L'.-c.-vod. 1 a.; Dennery y G. Lemoine [F: 16/11/1846] [E: 3/1/1852]

Au printemps.-c.-vod. 1 a. v.; Laluyé [F: 5/4/1854] [E: 8/3/1859]

Avocat du diable, $L^{\prime}$.-c. 1 a.; Marc-Michel y Choler [F: 27/11/1858] [E: 13/2/1859]

Avocats, Les.-c.-vod. 3 a.; Dumanoir y Clairville [F: 9/8/1852] [E: 10/5/1859]

Baiser de l'étrier, Le.-esc. de la «vie de garçon»; Brisebarre, Ancelot y Nyon [F: 19/ 4/1850] [E: 22/2/1858]

Bal du prisonnier, Le .-c.-vod. 1 a.; Guillard y Decourcelle [F: 27/10/1849] [E: 4/2/ 1858]

Baron de Fourchevif, Le.-c. 1 a.; Labiche y Jolly [F: 15/6/1859] [E: 5/2/1860]

Bataille de dames. - c. 3 a. pr.; Scribe y Legouvé [F: 17/3/1851] [E: 7/11/1852]

Bénéficiaire, Le.-c.-vod. 5 a.; Théaulon y Arago [F: 26/5/1825] [E: 12/11/1851]

Bocquet père et fils.-c.-vod. 2 a.; 'Laurencin, Marc-Michel y Labiche [F: 17/8/1840] [E: $6 / 12 / 1856]$

Bonhomme jadis, Le.-c. 1 a. pr.; Murger y Carré [F: 21/4/1852] [E: 28/2/1856]

Bougeoir, Le.-c. 1 a.; Caraguel [F: 21/5/1852] [E: 25/1/1860]

Bourgmestre de Sardam, Le, ou le Prince Charpentier .-vod. 2 a.; Mélesville, Merle y Boirie [F: 5/3/1825] [E: 20/12/1851]

Bourreau des crânes, Le.-c.-vod. 3 a. y prol.; Lafargue y Siraudin [F: 12/5/1853] [E: $8 / 12 / 1853]$

Bourse, La.-c. 5 a. v.; Ponsard [F: 6/5/1856] [E: 19/1/1857]

Brelan de troupiers. - c.-vod. 1 a.; Dumanoir y Arago [F: 9/10/1843] [E: 18/2/1858]

Bruno le fileur.-c.-vod. 2 a.; Cogniard, H. y T. Cogniard [F: 31/8/1837] [E: 31/10/1852]

Brutus, lâche César.-c. 1 a. con canc.; Rosier [F: 2/6/1849] [E: 16/11/1851]

Cabaret de Lustucru, Le.—c.-vod. 1 a.; Jaime, Arago y Dumanoir [F: 24/2/1838] [E: 16/ $1 / 1858]$

Cachemire vert!, Le.-c. 1 a.; Dumas, A. y Nus [F: 15/12/1849] [E: 18/11/1853]

Calife de la rue Saint-Bon, Le.-esc. de la vida turca, con cuplés; Marc-Michel y Labiche [F: 7/12/1858] [E: 8/5/1860]

Camp des bourgeoises, Le.-c. 1 a. con cuplés; Dumanoir [F: 1/12/1855] [E: 17/10/1856]

Camp des révoltées, Le.-fant. 1 a.; Lurine y R. Deslandes [F: 17/7/1856] [E: 27/2/1858]

Caporal et la payse, Le.-c. 1 a.; Varin, P. de Kock y Garnier [F: 23/10/1841] [E: 23/ $11 / 1851]$

Catherine, ou la croix d'or.-c. 2 a. con canc.; Brazier y Mélesville [F: 2/5/1835] [E: $12 / 12 / 1852]$

Ce que la femme veut....-c.-vod. 2 a.; Duvert y Lauzanne [F: 1/4/1847] [E: 22/2/1852]

Cendrillon.-c. 5 a.; Barrière [F: 23/12/1853] [E: 12/4/1859]

Clermont ou une femme d'artiste.-c.-vod. 2 a.; Scribe y Van der Burch [F: 30/3/1838] [E: 4/3/1852]

Code des femmes, Le.-c. 1 a.; Dumanoir [F: 18/10/1845] [E: 6/12/1853]

Coiffeur et le perruquier, Le.- -vod. 1 a.; Scribe, Mazères y Saint-Laurent [F: 15/1/1824] [E: 28/12/1851]

Commis et la grisette, Le.—vod. 1 a.; De Kock, P y Labie [F: 10/7/1834] [E: 2/12/1851]

Comtesse de Tonneau ou Les deux cousines, La.—c--vod. 2 a.; Théaulon, Decomberousse y Chazet [F: 13/4/1837] [E: 24/4/1860]

Confident, Le.-c.-vod. 1 a.; Scribe y Mélesville [F: 5/1/1826] [E: 28/4/1861]

Copiste Le.-c. 1 a. pr.; Meilhac [F: 3/8/1857] [E: 7/4/1858] 
Corde sensible, La.-vod. 1 a.; Clairville y Lambert-Thiboust [F: 8/10/1851] [E: 28/9/ 1852]

Coucher d'une étoile, Le.-c. 1 a.; Gozlan [F: 17/10/1851] [E: 1/1/1856]

Crise, La.-c. cost. 4 a.; Feuillet [F: 7/3/1854] [E: 14/2/1860]

Crochets du père Martin, Les.-pz. 3 a.; Cormon y Grangé [F: 3/8/1858] [E: 11/1/1859]

Croque-poule.-c.-vod. 1 a.; Rosier [F: 2/11/1849] [E: 18/2/1858]

Chambre à deux lits.-c.-vod. 1 a.; Rose, G. [E: 20/1/1852]

Chanoinesse, La.-c.-vod. 1 a.; Scribe y Cornu [F: 31/12/1833] [E: 29/9/1852]

Chapeau d'un horloger, Le.-c. 1 a.; Girardin, E. [F: 16/12/1854] [E: 31/10/1856]

Chatte métamorphosée [en Femme], La.-folie vod. 1 a.; Scribe, Mélesville y Bouchardy [F: 3/3/1827] [E: 8/3/1859]

Chef d'oeuvre inconnu, Le.-dr. 1 a. pr.; Lafont [F: 17/6/1837] [E: 17/10/1856]

Chevalier d'Essone, Le.-c.-vod. 3 a.; Dupeuty y Bourgeois [F: 19/10/1847] [E: 7/4/1861]

Chevalier de Saint Georges, Le.-c.-vod. 3 a. con canc.; Beauvoir, R. [F: 15/2/1840] [E: 28/9/1852]

Chevalier du Guet, Le.-c. 2 a.; Lockroy [F: 9/9/1840] [E: 1/12/1853]

Chevaliers du pince-nez, Les.-c.-vod. 2 a.; Grangé, P. Deslandes y Lambert-Thiboust [F: 16/8/1859] [E: 11/5/1861]

Cheveu Blanc, Le.-c. 1 a. pr.; Feuillet [F: 16/3/1860] [E: 16/4/1861]

Dalila.-dr. 3 a. 6 cdr.; Feuillet [F: 29/5/1857] [E: 23/5/1860]

Dame aux camélias, La.-dr.-c. con canc. 5 a.; Dumas, A. (h.) [F: 2/2/1852] [E: 26/4/ 1856]

Dame blanche, La .-óp. cóm. 3 a.; Boïeldieu, F. A.; lib.: Scribe [F: 10/12/1825] [E: $22 / 10 / 1853]$

Débutant, Le, ou l'amour et la comédie.-vod. 1 a.; Desnoyer [F: 20/4/1841] [E: 9/1/ 1852]

Demi-monde, Le.-c. 5 a.; Dumas, A. (h.) [F: 20/3/1855] [E: 21/10/1856]

Démon de la nuit, Le.-c.-vod. 2 a.; Bayard y Arago [F: 18/5/1836] [E: 5/11/1858]

Dépit amoureux, Le.-c. 2 a.; Molière [E: 16/1/1852]

Deux Anges Gardiens, Les.-c.-vod. 1 a.; Deslandes, P. [F: 21/8/1848] [E: 28/1/1852]

Deux aveugles, Les.-c. con cuplés 1 a.; Carmouche y Courcy [F: 3/2/1823] [E: 12/3/ 1856]

Deux dames au violon.-pochade 1 a. ; Dupeuty y Cormon [F: 11/5/1841] [E: 19/1/1856]

Deux divorces, Les.-c.-vod. 1 a.; Cogniard, H. y T. Cogniard [F: 2/11/1831] [E: 5/11/ 1851]

Deux frères [ou la réconciliation], Les.-c. 4 a. pr.; Kotzebue (al.) / Weiss, Jauffret y Patrat (trads. del al.) [F: 29/7/1799] [E: 16/11/1858]

Deux merles blancs, Les.-c.-vod. 3 a.; Labiche y Delacour [F: 12/5/1858] [E: 20/3/1860]

Dieu vous bénisse.-c.-vod. 1 a.; Ancelot y Duport [F: 14/2/1839] [E: 14/11/1852]

Diplomate, Le.-c.-vod. 2 a.; Scribe y Delavigne [F: 23/10/1827] [E: 28/11/1852]

Diplomatie du ménage, La.-prov. 1 a.; Berton, C. [F: 6/1/1852] [E: 16/3/1859]

Dos à dos.-c. 1 a. pr.; Beauvoir, A.R. [E: 2/4/1859]

Drame interrompu, Le.-pz. cóm. de grande espt.; [E: 29/12/1853]

Droits de l'homme, Les.-c. 2 a. pr.; Prémaray [F: 5/11/1851] [E: 9/12/1855]

Duc Job, Le.-c. 4 a. pr.; Laya [F: 4/11/1859] [E: 1/5/1860]

École des femmes, l'.-c. 5 a. v.; Molière [F: 26/12/1662] [E: 14/1/1853]

Edgard et sa bonne.-c. 1 a. con canc.; Labiche y Marc-Michel [F: 16/10/1852] [E: 1/ 12/1855]

Effrontés, Les.-c. 5 a. pr.; Augier [F: 10/1/1861] [E: 20/3/1861]

Égarements d'une canne et d'un parapluie, Les.-folie-vod.; Duvert y Lauzanne [F: 28/ 1/1843] [E: 2/1/1857]

Elle est folle!.-c. 2 a. con canc.; Mélesville [F: 20/1/1835] [E: 9/1/1852] 
Embrassons-nous, Folleville.-c.-vod. 1 a.; Labiche y Lefranc [F: 6/3/1850] [E: 24/10/ 185்3]

En pénitence ou les époux à la Bastille.-c.-vod. 1 a.; Bourgeois [F: 7/3/1841] [E: 15/ 5/1859]

En pension chez son groom.—vod. 1 a.; Marc-Michel y Labiche [F: 2/2/1856] [E: 19/2/ 1859]

Enfants terribles, Les.--esc. de Gavarni con cuplés, 2 a.; Clairville y Lambert-Thiboust [F: 30/8/1856] [E: 24/3/1860]

Enfers de Paris, Les.-c.-vod. 5 a. y 7 cdr.; Beauvoir, R. [F: 16/9/1853] [E: 8/4/1860]

Enseignement mutuel, $L^{\prime}$.- vod. 1 a.; Barrière y Decourcelle [F: 20/1/1851] [E: 22/2/ 1852]

Erreurs du bel âge, Les.-vod. 1 a.; Xavier, Varin y Dumoustier [F: 9/2/1854] [E: 7/1/ 1856]

Escadron volant de la Reine, L'.-c.-vod. 1 a.; Dumanoir y Lafargue [F: 7/5/1845] [E: $13 / 3 / 1860]$

Estelle [ou le père et la fille].-c.-vod. 1 a.; Scribe [F: 7/11/1834] [E: 19/2/1856]

Être aimé ou mourir!.—c.-vod. 1 a.; Scribe y Dumanoir [F: 10/3/1835] [E: 14/1/1858]

Eugénie ou la petite orpheline.-vod. 1 a.; [E: 14/1/1854]

Extases de Mr. Hochenez, Les.-c. 1 a.; Marc-Michel [F: 9/12/1850] [E: 4/3/1859]

Famille improvisée, La.—vod. 1 a.; Dupeuty, Duvert y Brazier [F: 5/7/1831] [E: 18/12/ 1852]

Famille Lambert, La.-c. 2 a. pr.; Gozlan [F: 28/4/1857] [E: 23/10/1858]

Fausse adultère, La.--dr. espt. 5 a. y 7 cdr.; Dennery [F: 29/12/1856] [E: 27/10/1858]

Faux bons hommes, Les. -c. 4 a.; Barrière y Capendu [F: 11/11/1856] [E: 5/2/1859]

Fée Cocotte, La.-c.-vod. 1 a.; Mélesville y Xavier [F: 14/5/1851] [E: 20/1/1854]

Fées de Paris, Les.-c.-vod. 2 a.; Bayard [F: 3/12/1841] [E: 24/12/1851]

Femme aux æeufs d'or, La.-vod. 1 a.; Dumanoir y Clairville [F: 22/11/1852] [E: 22/12/ 1855]

Femme qui trompe son mari, La.-c.-vod. 1 a.; Lemoine-Moreau, E. y Delacour [F: 17/ 7/1851] [E: 11/12/1858]

Femmes fortes, Les.-c. 3 a. pr.; Sardou [F: 31/12/1860] [E: 16/4/1861]

Femmes qui pleurent, Les.—c. 1 a.; Siraudin y Lambert-Thiboust [F: 12/4/1858] [E: 19/ $11 / 1858]$

Femmes terribles, Les.-c. 3 a. pr.; Dumanoir [F: 20/3/1858] [E: 21/12/1858]

Ferme de Primerose, La.—c.-vod. 1 a.; Cormon y Dutertre [F: 27/6/1851] [E: 2/3/1856]

Feu à una vielle maison, Le.-c.-vod. 1 a.; Lemoine, G. [F: 28/11/1857] [E: 9/6/1859]

Feu au couvent, Le.-c. 1 a. pr.; Barrière [F: 13/3/1860] [E: 18/5/1860]

Feu, le capitaine Octave!.-c. 1 a.; Plouvier y Adenis [F: 19/3/1859] [E: 5/2/1860]

Fiammina, La.-c. 4 a. pr.; Uchard [F: 12/3/1857] [E: 23/1/1858]

Fils naturel, Le.-c. 4 a. y pról.; Dumas, A. (h) [F: 16/1/1858] [E: 23/3/1858]

Fille de Dominique, La.-c.-vod. 1 a.; Villeneuve y Livry [F: 22/6/1833] [E: 28/12/1851]

Filles de Marbre, Les.-dr. 5 a. con canc.; Barrière y Lambert-Thiboust [F: 17/5/1853] [E: 4/12/1855]

Fiole de Cagliostro, La.-vod. 1 a.; Bourgeois, Dumanoir y Brisebarre [F: 23/12/1835] [E: 18/10/1852]

Flaneuse.-vod. 1 a.; Forges y Saint-Yves [F: 24/2/1855] [E: 6/5/1858]

Folies amoureuses, Les.-c. 3 a. v.; Regnard [F: 15/1/1704] [E: 14/1/1853]

Folies dramatiques, Les._-vod. 5 a.; Dumanoir y Clairville [F: 2/3/1853] [E: 25/12/1858]

Françoise et Nicolas.-[E: 22/1/1860]

Frisette.-c.-vod. 1 a.; Labiche y Lefranc [F: 28/4/1846] [E: 31/5/1858]

Frontin, mari garçon.-c.-vod. 1 a.; Scribe y Mélesville [F: 18/1/1821] [E: 7/2/1854] 
Gabrielle.-c. 5 a. v.; Augier [F: 15/12/1849] [E: 4/1/1854]

Gamin de Paris, Le.-vod. 2 a.; Bayard y Van der Burch [F: 30/1/1836] [E: 1/2/1852] Gant et l'éventail, Le.-c. 1 a. ; Bayard y T. Sauvage [F: 6/6/1846] [E: 24/11/1856]

Gants jaunes, Les.-vod. 1 a.; Bayard [F: 6/3/1835] [E: 27/10/1853]

Gendre de Mr. Poirier, Le.—c. 4 a. pr.; Augier y Sandeau [F: 8/4/1854] [E: 1/12/1856] Geneviève [, ou la Jalousie paternelle].—c.-vod. 1 a.; Scribe [F: 30/3/1846] [E: 5/11/1851] Gentil-Bernard.-c. 5 a. con cuplés; Dumanoir y Clairville [F: 16/3/1846] [E: 15/5/1858] Grace de Dieu, La.-dr. 5 a. con canc.; Lemoine, G. [F: 16/1/1841] [E: 12/2/1852] Granair du Chalet.-[E: 6/3/1856]

Henriette et Charlot.-vod. 1 a.; Xavier y Varin [F: 15/5/1847] [E: 16/1/1856]

Héritière, L'.-c.-vod. 1 a.; Scribe y Delavigne [F: 20/12/1823] [E: 3/10/1852]

Homme blasé, L'.-c.-vod. 2 a.; Duvert y Lauzanne [F: 18/11/1843] [E: 18/10/1853]

Homme qui a vécu, $L$ '.-c.-vod. 2 a.; Dumanoir y Lafargue [F: 29/1/1857] [E: 17/5/1859] Honneur est satisfait, L'-c. 1 a. pr.; Dumas, A. (h.) [F: 19/6/1858] [E: 15/12/1858]

Honneur et l'argent, L'.-c. 5 a. v.; Ponsard [F: 11/3/1853] [E: 12/11/1856]

Horace et Caroline.-c.-vod. 2 a.; Bayard y Biéville [F: 19/5/1848] [E: 2/3/1858]

Horace et Lydie.-c. 1 a. v.; Ponsard [F: 19/6/1850] [E: 30/1/1856]

Il faut qu'une porte soit ouverte ou fermée.-prov. 1 a.; Musset [F: 7/6/1848] [E: 12/12/ 1852]

Île de Calypso, L'.-opta. bufa 1 a. con b.; lib.: Julian [F: 3/12/1857] [E: 25/1/1860] Image, L'-Cc.-vod. 1 a.; Scribe y T. Sauvage [F: 17/4/1845] [E: 24/10/1852]

Indiana et Charlemagne.-vod. 1 a.; Bayard y Dumanoir [F: 26/2/1840] [E: 14/11/1851] Invitation à la valse, $L^{\prime}$-—c. 1 a. pr.; Dumas, A. [F: 18/6/1857] [E: 4/1/1858]

Irène ou le magnétisme.—c.-vod. 2 a.; Scribe y Lockroy [F: 2/2/1847] [E: 19/2/1859] J'ai mangé mon ami.--vod. 1 a.; Xavier, Varin y Boyer [F: 7/2/1850] [E: 11/2/1856] Jacquot.—vod. 1 a.; Gabriel, J. y Vermond [F: 18/10/1843] [E: 16/12/1852]

Je dîne chez ma mère.-c. con cuplés 1 a.; Decourcelle y Lambert-Thiboust [F: 31/12/ 1855] [E: 23/4/1856]

Je suis enrhumé du cerveau.-[E: 9/1/1856]

Jeanne Mathieu [ ou être aimé pour soi-même].-c.-vod. 1 a.; Fournier [F: 28/8/1848] [E: 25/11/1852]

Jeanne qui pleure et Jeanne qui rit.-c. 4 a. pr.; Dumanoir y Keraniou [F: 4/4/1860] [E: $22 / 5 / 1861]$

Jeune mari, Le.-c. 3 a. pr.; Mazères [F: 26/11/1826] [E: 5/10/1852]

Jeunes gens, Les.-c. 3 a.; Laya [F: 10/3/1855] [E: 20/12/1856]

Jobin et Nanette.-c.-vod. 1 a.; Carré y Battu [F: 1/5/1849] [E: 21/10/1852]

Joie fait peur, La.-c. 1 a. pr.; Girardin, D. [F: 25/2/1854] [E: 13/3/1856]

La Fille bien gardée.-c.-vod. 1 a.; Labiche y Marc-Michel [F: 6/9/1850] [E: 14/1/1854]

Lait d'ânesse, La.-c.-vod. 1 a.; Gabriel, J. [F: 25/4/1846] [E: 22/2/1852]

Lanciers, Les.-vod. 1 a.; Cormon y Grangé [F: 9/2/1857] [E: 8/2/1858]

Laquais d'Arthur, Le.-c. 1 a. pr.; Lordereau [F: 13/3/1854] [E: 16/5/1858]

Lectrice, La.-c.-vod. 2 a.; Bayard [F: 16/9/1834] [E: 10/4/1856]

Léonide, ou la Vieille de Suresne.-c.-vod. 3 a.; Dupeuty, Villeneuve y Saint-Hilaire [F: 17/1/1824] [E: 19/2/1858]

Ligne droite, La.-c. 1 a. pr.; Monnier, M. [F: 24/10/1854] [E: 3/4/1856]

Lion empaillé, Le.-c.-vod. 2 a.; Gozlan [F: 3/10/1848] [E: 6/11/1856]

Lion et le rat, Le .-c.-vod. 1 a.; Leuven y Vermond [F: 12/1/1848] [E: 29/4/1858]

Livre III, chapitre I.-c. 1 a. pr.; Pierron y Laferrière [F: 19/9/1851] [E: 31/1/1852]

Louis XV à dix ans.-c.-vod. 1 a.; [E: 7/2/1854]

Louise, ou la Réparation.-c.-vod. 2 a.; Scribe, Mélesville y Bayard [F: 16/11/1829] [E: 3/10/1852] 
Louisette ou la chanteuse des rues.-C.-vod. 2 a.; Marc-Michel y Fontaine [F: 13/4/1840] [E: 3/10/1852]

Ma femme est troublée.-c. 1 a.; Dumanoir y Decourcelle [F: 15/3/1861] [E: 17/5/1861]

Ma femme et mon parapluie._vod. 1 a.; Laurencin [F: 23/6/1834] [E: 16/12/1852]

Mad. et Mr. Pinchon.-c.-vod. 1 a.; Bayard, Dumanoir y Dennery [F: 5/4/1838] [E: 24/ $11 / 1853]$

Madame Bijou.-c.-vod. 1 a.; Lurine y R. Deslandes [F: 24/1/1856] [E: 26/3/1859]

Madame Camus et sa demoiselle.-[E: 23/1/1856]

Madame est de retour.-c. prov. 1 a.; Duflot y Desarbres [F: 13/11/1853] [E: 5/4/1861]

Madame Gibou et madame Pochet.-vod. 2 a.; Dumersan [F: 20/2/1832] [E: 27/12/1852]

Madame Roger Bontemps. -vod. 1 a.; Clairville y Jallais [F: 22/2/1856] [E: 24/4/1858]

Madame veuve Larifla.-vod. 1 a.; Labiche y Choler [F: 25/1/1848] [E: 28/1/1852]

Madelon Friquet.-c.-vod. 2 a.; Rougemont y Dupeuty [F: 1/10/1835] [E: 9/4/1859]

Mademoiselle Dangeville.—c. 1 a. con canc.; Villeneuve y Livry [F: 10/11/1828] [E: 23/ 10/1858]

Mademoiselle de Belle-Isle.-c. 5 a.; Dumas, A. [E: 10/10/1852]

Mademoiselle de la Seiglière.-c. 4 a. pr.; Sandeau [F: 4/11/1851] [E: 28/2/1852]

Mademoiselle mon frère.-vod. 1 a.; Clairville [F: 28/3/1858] [E: 25/1/1860]

Mâitre d'école [, ou la distribution des prix], Le._vod. 1 a.; Lockroy y Bourgeois [F: 20/3/1841] [E: 26/12/1851]

Maîtresse de langues, La.—c. 1 a.; Saint-Georges, Leuven y Dumanoir [F: 21/2/1838] [E: 26/3/1856]

Maîtresse du mari, La.—c. con "canc.; Duflot y Desarbres [F: 3/10/1854] [E: 28/2/1856]

Malade imaginaire, Le .-c. 3 a. pr.; Molière [F: 10/2/1673] [E: 22/12/1853]

Malheurs d'un amant heureux, Les.-c.-vod. 2 a.; Scribe [F: 29/1/1833] [E: 14/11/1852]

Mam' zell' Rose.—vod. 1 a.; Decourcelle y Bercioux [F: 29/10/1852] [E: 25/3/1858]

Mam'zelle fait ses dents.-c.-vod. 1 a.; Labiche y Marc-Michel [F: 9/4/1851] [E: 26/1/ 1854]

Maman Sabouleux.-c.-vod. 1 a.; Labiche y Marc-Michel [F: 12/3/1852] [E: 14/2/1854]

Marchand de jouets d'enfant, Le.-c.-vod. 1 a.; Mélesville y Guillard [F: 10/4/1848] [E: 26/3/1856]

Margot.-vod. 1 a.; Clairville y Milon [F: 16/10/1837] [E: 30/11/1852]

Marguerite.-c. 3 a. con cuplés; Ancelot, V. [F: 3/10/1840] [E: 18/1/1852]

Mari à la campagne, Le.-c. 3 a.; Bayard y Vailly [F: 3/6/1844] [E: 3/12/1855]

Mari á la ville..., Le .-c.-vod. 2 a.; Varin [F: 3/8/1837] [E: 29/9/1852]

Mari de la dame de choeurs, Le .- vod. 2 a.; Bayard y Duvert [F: 12/12/1836] [E: 8/10/ 1852]

Mari de la veuve, Le.-c.-vod. 1 a. pr.; Bourgeois, Gabriel, J. y A. Dumas [F: 4/4/1832] [E: $17 / 10 / 1852]$

Mariage de raison, Le.-c.-vod. 2 a.; Scribe y Varner [F: 10/10/1826] [E: 8/12/1852]

Mariage extravagant, Le.-c.-vod. 1 a.; Désaugiers [F: 8/9/1812] [E: 20/1/1858]

Maris me font toujours rire, Les.-c.-vod. 2 a.; Jaime [F: 20/11/1854] [E: 5/4/1856]

Marquise de Pretintaille, La.-c.-vod. 1 a.; Bayard y Dumanoir [F: 23/4/1836] [E: 5/12/ 1856]

Marquise de Senneterre, La.-c. 3 a. pr.; Mélesville y Duveyrier [F: 24/10/1837] [E: 13/ $1 / 1856]$

Marraine, La.-c.-vod. 1 a.; Scribe, Lockroy y Chabot [F: 27/11/1827] [E: 12/11/1851]

Marseillais à Paris, Le.-esc. cóm.; Bourget; m.: L. Bousquet [E: 23/12/1852]

Massacre d'un innocent, Le._vod. 1 a.; Marc-Michel y Varin [F: 9/3/1855] [E: 22/5/ 1859]

Mathias l'invalide.—c.-vod. 2 a.; Bayard y L. Picard [F: 5/6/1838] [E: 16/11/1851] 
Mathilde ou la jalousie.-c. 3 a. con canc.; Laurencin y Bayard [F: 3/6/1835] [E: 20/1/ 1859]

Médecin des enfants, Le.-dr. 5 a.; Bourgeois y Dennery [F: 25/10/1855] [E: 7/12/1856]

Mêli-mêlo de la rue Meslay, Les.-c.-vod. 1 a.; Marc-Michel y Choler [F: 9/9/1859] [E: 12/2/1860]

Mémoires du Diable, Les.-c.-vod. 3 a.; Arago y Vermond [F: 2/3/1842] [E: 7/12/1851]

Mercadet.-c. 3 a. pr.; Balzac [F: 24/8/1851] [E: 28/11/1851]

Mère de famille, La.-c.-vod. 1 a.; Dennery y G. Lemoine [F: 21/1/1846] [E: 19/12/ 1855]

Mère Michel aux Italiens, La .-esc. cóm.; [E: 15/12/1853]

Meunière de Marly, La.-c.-vod. 1 a.; Mélesville y Duveyrier [F: 12/4/1840] [E: 30/10/ 1852]

Michel et Christine.-c.-vod. 1 a.; Scribe y Dupin [F: 3/12/1821] [E: 19/10/1852]

Michel Perrin.—c.-vod. 2 a.; Mélesville y Duveyrier [F: 19/2/1834] [E: 23/12/1852]

Midi à quatorze heures.-c.-vod. 1 a.; Barrière [F: 9/4/1851] [E: 24/12/1856]

Militaire et pensionnaire.-vod. 1 a.; Brisebarre y Lustières [F: 6/3/1851] [E: 19/1/1860]

Misanthrope et l'auvergnat, Le.-c. 1 a. con cuplés ; Lubize, Labiche y Siraudin [F: 19/ 8/1852] [E: 2/11/1853]

Mme. Bertrand et Mlle. Raton.-c.-vod. 1 a.; Dumanoir y Lafargue [F: 25/4/1851] [E: $13 / 10 / 1852]$

Moiroud et Compagnie.-c.-vod. 1 a.; Bayard y Devorme [F: 4/5/1836] [E: 5/10/1852]

Mon Isménie!.-c. 1a. con cuplés; Labiche y Marc-Michel [F: 17/12/1852] [E: 26/12/ 1855]

Monsieur va au cercle.-vod. 1 a.; Delacourt y Godoy [F: 2/4/1856] [E: 30/10/1858]

Moulin a paroles, Le.-c.-vod. 1 a.; Gabriel, J. y Dupeuty [F: 8/6/1847] [E: 28/1/1852]

Mousquetaires de la Reine, Les.—óp. cóm. 3 a.; Halévy; lib.: Saint-Georges [F: 3/2/1846] [E: 10/10/1853]

Mystères de l'été, Les.-c.-vod. 5 a.; Lambert-Thiboust y Delacourt [F: 9/6/1853] [E: 14/5/1860]

Niaise, La.-c. 4 a.; Mazères [F: 19/6/1848] [E: 27/10/1856]

Noces de Merluchet, Les.-vod. 3 a.; Delacour y Jaime [F: 3/7/1854] [E: 26/1/1856]

Omelette fantastique, $L^{\prime}$.- - vod. 1 a.; Duvert y Boyer [F: 22/8/1842] [E: 23/10/1852]

On demande un gouverneur.-c.-vod. 2 a.; Decourcelle y Jaime [F: 12/4/1853] [E: 14/4/ 1858]

Oubli, L', ou La Chambre nuptiale.-vod. 1 a.; Duport [F: 18/6/1830] [E: 28/9/1852]

Ours et le Pacha, L'.-folie-vod. 1 a.; Scribe y Xavier [F: 10/2/1820] [E: 24/12/1851]

Pantins de Violette, Les.-opta. 1 a.; Adam; lib.: Battu [F: 29/4/1856] [E: 4/4/1861]

Par droit de conquête.-c. 3 a. pr.; Legouvé [F: 7/6/1855] [E: 28/11/1858]

Partie de piquet, La.-c.-vod. 1 a.; Fournier y Meyer [F: 5/2/1854] [E: 1/2/1858]

Pas de fumée sans feu.-c. prov. 1 a. con cuplés ; Bayard [F: 7/9/1849] [E: 16/11/1852]

Pattes de Mouche, Les.-c. 3 a. pr.; Sardou [F: 15/5/1860] [E: 1/5/1861]

Pauvre Jacques!.-c.-vod. 1 a.; Cogniard, H. y T. Cogniard [F: 15/9/1835] [E: 27/10/ 1852]

Pensionnaire mariée, La.-c.-vod. 1 a.; Scribe y Varner [F: 3/11/1835] [E: 16/1/1857]

Perdrix rouge, La.-c.-vod. 1. a.; Decourcelle y Lambert-Thiboust [F: 22/7/1852] [E: 27/ 4/1859]

Perle de la Canebière, La.-c. 1 a. con canc.; Marc-Michel y Labiche [F: 10/2/1856] [E: 19/2/1860]

Petit cochon de Barbarie, Le.-[E: 28/2/1856]

Petit fils, Le.-c.-vod. 1 a.; Bayard y Varner [F: 8/5/1846] [E: 19/12/1855]

Petite cousine, La.-c.-vod. 1 a.; Decourcelle y Barrière [F: 7/1/1849] [E: 30/10/1858] 
Petite Fadette, La.-c.-vod. 2 a.; Bourgeois y Lafont [F: 20/4/1850] [E: 25/2/1858] Petites mains, Les. - c. cost. 3 a.; Labiche y E. Martin [F: 28/11/1859] [E: 31/1/1860] Petites misères [de la vie humaine], Les.-vod. 1 a.; Clairville [F: 8/7/1843] [E: 4/11/ 1858]

Petits moyens, Les.-c.-vod. 1 a.; Lemoine, G., Labiche y Decourcelle [F: 6/11/1850] [E: 8/12/1856]

Philippe.-c.-vod. 1 a.; Scribe, Mélesville y Bayard [F: 19/4/1830] [E: 19/10/1856]

Philtre champenois, Le.-c.-vod. 1 a.; Mélesville y Brazier [F: 19/7/1831] [E: 10/12/1851]

Piano de Berthe, Le.-c. con canc. 1 a.; Barrière y Lorin [F: 20/3/1852] [E: 14/1/1853]

Piccolet [ ou l'électeur et le candidat].—c.-vod. 1 a.; Lefranc, Labiche y Montjoie [F: 30/9/1852] [E: 23/12/1856]

Plus on est de fous....-vod. 1 a.; Najac [F: 12/6/1858] [E: 25/5/1861]

Polka en province, La.-folie-vod. 1 a.; Decomberousse [F: 6/4/1844] [E: 17/1/1852]

Pont cassé, Le .-c.-vod. 1 a.; Duvert y Lauzanne [F: 10/10/1850] [E: 20/3/1858]

Pour et le contre, Le.-c. 1 a. pr.; Feuillet [F: 24/10/1853] [E: 1/12/1855]

Pourquoi?.-c.-vod. 1 a.; Lockroy y Bourgeois [F: 14/6/1833] [E: 12/3/1861]

Premier coup du canif, Le.-c.-vód. 2 a.; Bourgeois y Brisebarre [F: 14/8/1848] [E: 8/3/ 1856]

Premières amours, Les.-c.-vod. 1 a.; Scribe [F: 12/11/1825] [E: 23/11/1851]

Premières armes de Richelieu, Les.-C.-vod. 2 a. con cuplés; Bayard y Dumanoir [F: 3/ 12/1839] [E: 19/11/1851]

Princesse et Charbonnière.-c.-vod. 1 a.; Bayard y Dumanoir [F: 13/4/1850] [E: 31/1/ 1854]

Princesses de la rampe, Les.-c. 2 a. con canc.; Lambert-Thiboust y Beauvallet [F: 26/ 2/1857] [E: 8/5/1858]

Protegée [sans le savoir], La.-c.-vod. 1 a.; Scribe [F: 5/12/1846] [E: 9/11/1853]

Pulkriska et Léontino.-pochade con cuplés; La Rounat y Montjoie [F: 6/11/1853] [E: 31/12/1858]

Quand l'amour s'en va.-c.-vod. 1 a.; Laurencin y Marc-Michel [F: 5/8/1843] [E: 11/3/ 1858]

Quand on attend sa bourse.-c.-vod. 1 a. con canc.; Marc-Michel y Laurencin [F: 24/5/ 1853] [E: 3/5/1859]

Quand on veut tuer son chien.-prov. 1 a.; Barrière y Lorin [F: 30/4/1853] [E: 25/10/ 1856]

Quart de monde, Le.-par. vod. cóm. 1 a.; Clairville y Lambert-Thiboust [F: 18/4/1855] [E: 8/11/1856]

Quatorze de dames.-c.-vod. 1 a.; Gabriel, J. y Dupenty [F: 17/2/1854] [E: 24/4/1858] Question d'Orient, La.-vod. 1 a.; [E: 9/12/1855]

Qui se dispute s'adore.-prov. 1 a.; De Kock, H. y Potier [F: 21/8/1850] [E: 28/11/1858]

Qui se ressemble se gêne.-c.-vod. 1 a.; Marc-Michel, Fontaine y Peupin [F: 21/5/1842] [E: 1/1/1856]

Renaudin de Caen.-c.-vod. 2 a.; Duvert y Lauzanne [F: 24/3/1836] [E: 12/11/1853]

Rendez-vous bourgeois, Le.-op. bufa 1 a. pr.; Nicolo; lib.: Hoffman [F: 9/5/1807] [E: $1 / 1 / 1852]$

Ressources de Jonathas, Les.-c.-vod. 1 a.; Varin y D'Avrecourt [E: 9/5/1861]

Retour d'un corsaire, Le.-[E: 24/12/1855]

Riche d'amour.-c.-vod. 1 a.; Xavier, Duvert y Lauzanne [F: 20/11/1845] [E: 17/11/1853]

Risette ou Les millions de la mansarde.—vod. 1 a.; About [F: 8/8/1859] [E: 25/1/1860]

Rita l'espagnole.-dr. 4 a.; Desnoyer, Boulé y Chabot [F: 17/10/1837] [E: 29/10/1856]

Rivaux d'eux mèmes, Les.-c. 1 a. pr.; Pigault-Lebrun [F: 9/8/1798] [E: 19/11/1852]

Robert le diable.-aprop.-vod.; Villeneuve [F: 22/12/1831] [E: 27/2/1859] 
Robert Macaire.-pz. 4 a. 6 cdr.; Saint-Amand, Antier y Lemaître [E: 23/11/1852]

Roi de Cour, Le.-c.-vod. 1 a.; Decourcelle [F: 21/11/1848] [E: 23/3/1859]

Roman chez la portière, Le.-folie vod. 1 a.; Gabriel, J. y H. Monnier [F: 10/2/1855] [E: 29/4/1860]

Roman d'un jeune homme pauvre, Le.-c. 5 a. y 7 cdr.; Feuillet [F: 22/11/1858] [E: 17/ 4/1860]

Roman d'une heure [ou La folle gageure], Le.-c. 1 a. pr.; Hoffman [E: 31/1/1854]

Romulus.-c. 1 a. pr.; Dumas, A. [F: 17/1/1854] [E: 17/4/1858]

Rose de Saint-Flour, La.-opta. bufa 1 a.; Offenbach; lib.: Carré [F: 11/6/1856] [E: 14/ $11 / 1856]$

Rose des bois.-vod. 1 a.; Jaime; m.: Nargeot [F: 20/10/1855] [E: 22/5/1858]

Rose et Marguerite.-c. 3 a. con canc.; Desnoyer y Léonce [F: 14/9/1847] [E: 2/4/1859]

Rue de la Lune, La.--vod. 1 a.; Varin y Boyer [F: 14/2/1843] [E: 6/11/1852]

Sabot de Marguerite, Le.-c. 1 a. con canc.; Marc-Michel y Moreau [F: 24/10/1854] [E: $16 / 4 / 1856]$

Saltimbanques, Les.-c.-parada 3 a. con cuplés, Dumersan y Varin [F: 25/1/1838] [E: 24/10/1852]

Seconde année [ou à qui la faute?], La.-c.-vod. 1 a.; Scribe y Mélesville [F: 12/1/1830] [E: 19/10/1852]

Serment d'Horace, Le.-c. 1 a. pr.; Murger [F: 28/11/1860] [E: 25/4/1861]

Si Pontoise le savait!.-vod. 1 a.; Laurencin, Adenis y Tourte [F: 25/2/1860] [E: 31/5/ 1861]

Simplette, la chevrière.-vod. 1 a.; Cogniard, T. [F: 14/4/1839] [E: 20/5/1859]

Sire de Franc-Boisy, Le.-vod.-leyenda; Flan y Delteil [F: 14/7/1855] [E: 2/4/1859]

Sour de Jocrisse, La.-c.1 a. con canc. ; Varner y Duvert [F: 17/7/1841] [E: 24/12/ 1851]

Sous-clé.-c.-vod. 1 a.; Dumanoir, Leuven y Forges [F: 22/5/1833] [E: 5/12/1852]

Souvenirs de jeunesse, Les.-c.-vod. 4 a.; Lambert-Thiboust y Delacour [F: 2/9/1852] [E: 25/2/1859]

Suites d'un premier lit, Les.-c. 1 a. con canc. ; Marc-Michel y Labiche [F: 8/5/1852] [E: 9/3/1861]

Supplice de Tantale.-c.-vod. 1 a.; Duvert y Lauzanne [F: 31/10/1850] [E: 10/2/1852]

Tambour battant.--c.-vod. 1 a.; Decourcelle, Barrière y Morand [F: 30/10/1851] [E: 17/ 10/1852]

Tartuffe.-c. 5 a. v.; Molière [E: 31/10/1852]

Tasse cassée, La.-c.-vod. 1 a.; Vermond y Lubize [F: 8/2/1849] [E: 16/12/1851]

Testament de César Girodot, Le.-c. 3 a. pr.; Belot y Villetard [F: 30/9/1859] [E: 17/5/ 1861]

Tiridate [ou Comédie et tragédie].—c.-vod. 1 a.; Fournier [F: 15/4/1841] [E: 17/10/1856]

Titi à "Robert le diable".-par.; [E: 4/3/1859]

Toilettes tapageuses, Les.-c. 1 a. con cuplés; Dumanoir y Barrière [F: 4/10/1856] [E: $16 / 1 / 1857]$

Toinette et son carabinier.-croquis mus. 1 a.; Delaporte [F: 15/9/1856] [E: 15/2/1860]

Touriste et la Bergère, Le.-vod. 1 a.; [E: 26/12/1851]

Trembleurs, Les.-esc. de la vida burguesa con cuplés; Dumanoir y Clairville [F: 23/3/ 1861] [E: $13 / 5 / 1861$ ]

Triolet.-c.-vod. 1 a.; Clairville y Mercier [F: 7/10/1857] [E: 12/12/1858]

Trois épiciers, Les.-vod. cóm. 3 a.; Lockroy y Bourgeois [F: 20/1/1840] [E: 28/2/1860]

Tromb-Al-ca-zar.-disp. mus. 1 a.; Offenbach; lib. Dupeuty y Bourget [F: 3/4/1856] [E $4 / 5 / 1861]$

Trop beau pour rien faire.-c. 1 a. con cuplés ; Plouvier y Adenis [F: 13/11/1855] [E: $9 / 6 / 1859]$ 
Trop heureuse.-c. 1 a. con canc.; Ancelot y Leroux [F: 25/3/1837] [E: 12/3/1856]

Un ami acharné.-c.-vod. 1 a.; Labiche y Jolly [F: 19/1/1853] [E: 15/4/1860]

Un ami malheureux.-c.-vod. 2 a.; Royer y Vaëz [F: 31/1/1850] [E: 1/5/1859]

Un Bal du grand monde.-c.-vod. 1 a.; Varin y Desvergers [F: 7/6/1836] [E: 24/11/1853]

Un bal en robe de chambre.-esc.-vod. 1 a.; Labiche y Marc-Michel [F: 12/10/1950] [E: 31/1/1854]

Un caprice.-c. 1 a. pr.; Musset [E: 27/12/1855]

Un cœur de grand-mère.-c. 1 a. con cuplés ; Beauplan [F: 4/9/1846] [E: 26/4/1858]

Un cœur qui parle.-c.-vod. 1 a.; Choler y Desarbres [F: 26/4/1855] [E: 14/5/1859]

Un Changement de main.-c.-vod. 2 a.; Bayard y Lafont [F: 28/6/1845] [E: 18/10/1853]

Un chapeau de paille d'Italie.-c. 5 a. con canc.; Labiche y Marc-Michel [F: 14/8/1851] [E: $14 / 12 / 1851]$

Un chef de brigands. - vod. 1 a.; Varin y Marchais [F: 10/11/1851] [E: 2/1/1853]

Un duel sous le cardinal de Richelieu.-dr. 3 a. con cuplés; Lockroy y Badon [F: 8/4/ 1832] [E: 5/11/1851]

Un fils de famille.-c.-vod. 3 a.; Bayard y Desnoyer [F: 25/11/1852] [E: 23/3/1856]

Un garçon de chez Véry.-c. 1a.;'Labiche [F: 10/5/1850] [E: 8/5/1859]

Un gendre en surveillance.-c. con canc. 1 a.; Marc-Michel y Labiche [F: 11/12/1857] [E: $2 / 12 / 1858]$

Un mari brûlé.-c. 1 a. con canc.; Nus y E. Sauvage [F: 8/9/1852] [E: 17/4/1858]

Un mari en 150.-c.-vod. 1 a.; Najac [F: 7/4/1853] [E: 14/4/1860]

Un mari qui prend du ventre.-c.-vod. 1 a.; Labiche y Marc-Michel [F: 8/4/1854] [E: 20/3/1858]

Un mari qui se dérange.—c.-vod. 2 a.; Cormon y Grangé [F: 25/3/1846] [E: 26/12/1851]

Un mariage sous Louis XV.—c. 5 a.; Dumas, A. [F: 1/6/1841] [E: 2/1/1853]

Un monsieur et une dame.-c.-vod. 1 a.; Xavier, Duvert y Lauzanne [F: 27/2/1841] [E: 29/9/1852]

Un monsieur qui prend la mouche.-c. 1 a. con cuplés; Marc-Michel y Labiche [F: 25/ 3/1852] [E: 20/12/1852]

Un monsieur qui suit les femmes.-c.-vod. 2 a.; Barrière y Decourcelle [F: 18/11/1850] [E: 4/3/1852]

Un père prodigue.-c. cost. 5 a.; Dumas, A. (h) [F: 30/11/1859] [E: 7/3/1860]

Un petit bout d'oreille.-c. 1 a. pr.; Gozlan [F: 12/12/1857] [E: 4/5/1858]

Un scandale.-folie-vod. 1 a.; Duvert y Lauzanne [F: 18/1/1834] [E: 24/2/1856]

Un tigre du Bengale.—c. 1 a. con canc.; Brisebarre y Marc-Michel [F: 12/9/1849] [E: 1/ $1 / 1852]$

Un Turc pris dans une porte.-vod. 1 a.; Brisebarre y Nyon [F: 17/2/1849] [E: 27/4/1859]

Un ut de poitrine.-vod. 1 a.; Labiche y Lefranc [F: 2/5/1853] [E: 27/1/1859]

Une bonne qu'on renvoie. - - vod. 1 a.; La Rounat y Berthoud [F: 23/2/1851] [E: 5/2/1856]

Une dame de l'Empire.-c.-vod. 1 a.; Ancelot y Duport [F: 17/3/1834] [E: 3/12/1852]

Une dent sous Louis XV.-mon.; Labiche y Lefranc [F: 15/2/1849] [E: 19/11/1852]

Une embuscade a Tracklin.- - episodio militar; [E: 22/1/1860]

Une épreuve avant la lettre.-c.-vod. 1 a.; Cordelier-Delanou y Barbier [F: 14/2/1855] [E: 21/2/1860]

Une femme qui mord.-c.-vod. 1 a.; Blum [F: 7/8/1855] [E: 9/4/1859]

Une femme qui se grise.-vod.; Lambert-Thiboust [F: 8/1/1853] [E: 17/3/1861]

Une femme qui se jette par la fenêtre.-c.-vod. 1 a.; Scribe [F: 19/4/1847] [E: 3/1/1852]

Une fille de famille.-[E: 2/4/1856]

Une Fille terrible.-vod. 1 a.; Deligny [F: 16/12/1846] [E: 19/11/1852]

Une jeunesse orageuse.-c. 2 a. con cuplés; Desnoyer [F: 13/5/1842] [E: 26/1/1854]

Une maîtresse bien agréable.-c.-vod. 1 a.; De Kock, P. y Lambert-Thiboust [F: 15/11/

1857] [E: 5/2/1860] 
Une mauvaise nuit est bientôt passée.-c. prov. 1 a.; Honoré [F: 16/10/1849] [E: 10/1/ 1856]

Une nuit à Sebastopol.-[E: 22/1/1860]

Une position délicate.-c.-vod. 1 a.; Leonce y Bernard [F: 18/1/1836] [E: 28/11/1852]

Une tasse de thé.-c. 1 a. pr.; Nuitter y Derley [F: 28/9/1860] [E: 14/3/1861]

Une tempête dans un verre d'eau.-c. 1 a.; Gozlan [F: 18/12/1849] [E: 15/3/1859]

Valérie.-c. 3 a. pr.; Scribe y Mélesville [F: 21/12/1822] [E: 22/11/1851]

Vendetta, La.-vod. 1 a.; Dumanoir y Siraudin [F: 23/10/1842] [E: 18/12/1858]

Vert-vert.-c.-vod. 3 a.; Leuven y Deforges [F: 15/3/1832] [E: 25/11/1858]

Veuve au camélia, La.--esc. de la vida parisiense; Siraudin, Lambert-Thiboust y Delacour [F: 23/9/1857] [E: 13/3/1858]

Veuve de quinze ans, La.- - vod. 1 a.; Dupeuty y Siraudin [F: 1/7/1846] [E: 30/3/1859]

Vicomte de Létorières [ou l'art de se faire aimer], Le.-c. 3 a. con canc. ; Bayard y Dumanoir [F: 1/12/1841] [E: 12/1/1857]

Vicomte Giroflée [ou Celui que j'ai rêvé], Le.-c.-vod. 1 a.; Laurencin y Marc-Michel [F: 16/3/1846] [E: 1/2/1860]

Vicomtesse Lolotte, La.-c.-vod. 3 a.; Bayard y Dumanoir [F: 12/5/1847] [E: 2/3/1859]

Vie de bohème, La.-c. 5 a.; Barrière y Murger [F: 22/11/1849] [E: 13/2/1856]

Vieux garçon et le petite fille, Le.-c.-vod. 1 a.; Scribe y Delavigne [F: 24/5/1822] [E: 18/1/1854]

Viveurs de Paris, Les.-dr. 5 a. y 8 cdr.; Montépin [F: 14/9/1857] [E: 2/6/1859]

$X$ - c. 1 a. con cuplés ; Desarbres y Nuitter [F: 11/9/1858] [E: 14/4/1861]

Yelva.-vod. 2 p.; Scribe, Villeneuve y Desvergers [F: 18/3/1828] [E: 14/2/1852]

York.-c.-vod. 1 a.; Feuillet y Bocage [F: 1/7/1852] [E: 29/1/1859]

Zamore et Giroflée .-vod. 1 a.; [E: 13/12/1855] 


\section{RESUMEN}

El «Teatro Francés» de Madrid (1851-1861), por Pedro Ojeda e Irene Vallejo.

El objetivo de este trabajo es el análisis del teatro francés representado por compañías francesas en Madrid en la década de 1851 a 1861 y las repercusiones que tuvo para el mundo teatral de la época. En este período, durante nueve temporadas, los aficionados al teatro pudieron presenciar la puesta en escena de cerca de cuatrocientos textos dramáticos en francés, cuyos títulos se ofrecen en un apéndice. Aunque se ejecutaron comedias, dramas, óperas, operetas y otras modalidades, el género preferido fue el vaudeville.

Palabras clave: Teatro francés. Teatro español. Vaudeville. Siglo XIX.

\section{SUMMARY}

The objective of this study is to analize the French plays staged by French troupes in Madrid between 1851 and 1861 and the repercussion it had on the Spanish theater of that time. During these nine seasons theater-lovers had the opportunity to see nearly 400 French works in their original version, the titles of which are to be found in an appendix to this study. The works can be catalogued in a variety of subgenres - comedies, dramas, operas, operettas, etc.-, but Madrid theater-goers preferred vaudeville.

Key words: French theater. Spanish theater. Vaudeville. $19^{\text {th }}$ century. 